\title{
فاعلية مسرحة المناهج فى تمقيق بعض أهداف الدالة الأسية فى مادة الرياضيات لدى طالبات الصف الثانى الثانوى
}

\author{
إعداد \\ منى عبد المقصود عبد العزيز شنب \\ مدرس بقسم الإعلام التربوى \\ كلية التربية النوعية - جامعة المنوفية
}

ملخص البحث

هدفت هذه الدراسة إلى التعرف على فاعلية مسرحة المناهج فى مادة الرياضيات لدى طالبات الصف الثانى الثانوى وذلك عن طريق الكثف عما إذا كان هناك اختلاف فى تحصيل طالبات الصف الثانى الثانوى اللاتى درسن بالطريقة التقليدية وتحصيل الطالبات اللاتى درسن بمسرحة المناهج فى مادة الرياضيات ، واستخدمت الباحثة المنهج التجربي ، وطبقت الدراسة على عينة دن طالبات الصف الثانى الثانوى مكونة من ( . . . مفردة ) وتم تقسيمهم إلى . مفردة تمثل المجموعة التجريبية و • r مفردة تمثل المجموعة الضابطة.

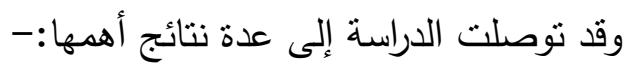

يوجد فرق دال إحصائياً بين متوسطى درجات المجموعة التجربيية ( اللاتى درسن باستخدم مسرحة المناهج ) وتلاميذ المجموعة الضابطة ( اللاتى درسن بالطريقة التقليدية ) فى القياس البعدى للاختبار التحصيلى لصالح طالبات المجموعة التجريبية. يوجد فرق دال إحصائياً بين متوسطى درجات المجموعة التجريبية فى التطبيق القبلى ومتوسط درجات المجموعة التجريبية فى التطبيق البعدى لصالح طالبات المجموعة التجربيية فى التطبيق البعدى • عدم وجود فروق دالة إحصائياً بين متوسط درجات المجموعة التجربيية ومتوسط درجات المجموعة الضابطة فى التطبيق القبلى على الاختبار التحصيلى. عدم وجود فروق دالة إحصائياً بين منوسط درجات المجموعة الضابطة فى التطبيق القبلى ومتوسط درجات المجموعة الضابطة فى التطبيق البعدى على الاختبار التحصيلى. 


\section{Abstract}

This study aimed to identify the effectiveness of the curriculum theatrics in mathematics among students of the second secondary class, by revealing whether there is a difference in the achievement of the second year students who studied in the traditional way and the collection of students who studied theatrical curricula in mathematics, and the researcher used the experimental approach.

The study was applied to a sample of second-year students consisting of (40 individuals) and they were divided into 20 items representing the experimental group and 20 items representing the control group

-There is a statistically significant difference between the mean scores of the experimental group (who studied using the theater curriculum) and the control group students (who studied in the traditional way) in the dimensional measurement of the achievement test in favor of the experimental group students

- There were no statistically significant differences between the mean scores of the experimental group and the mean scores of the control group in the pretest application to the achievement test. *There were no statistically significant differences between the mean score of the control group in the pre-application and the average score of the control group in the post application on the achievement test. 


\section{مقدمة}

تعد المرحلة الثانوية من المراحل التى يزداد الاهتمام بها ، فهى تتعلق بتحديد مصير

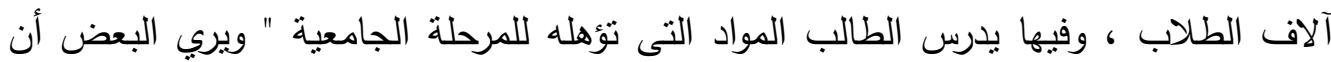

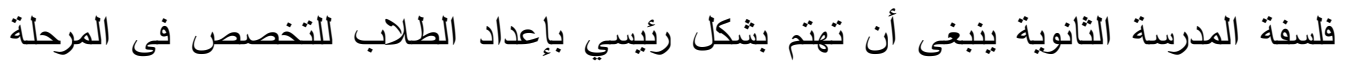

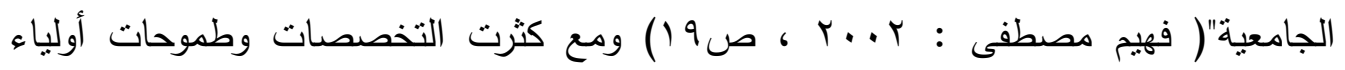

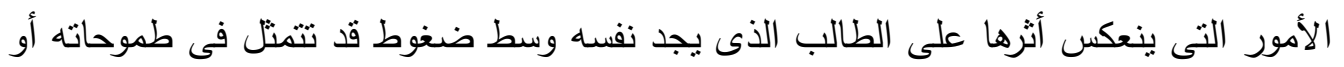

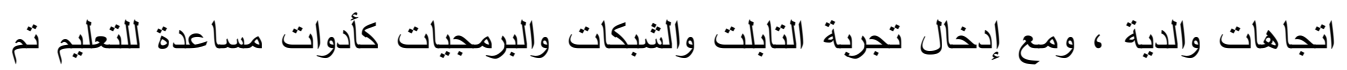

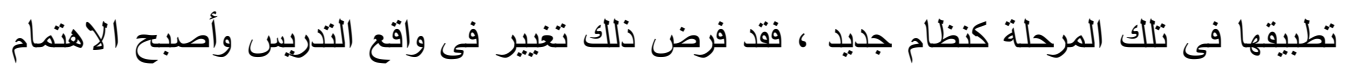

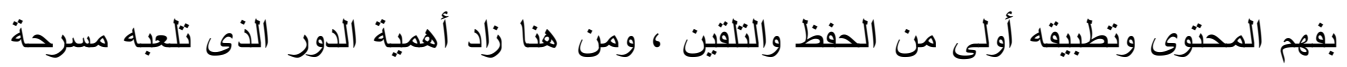

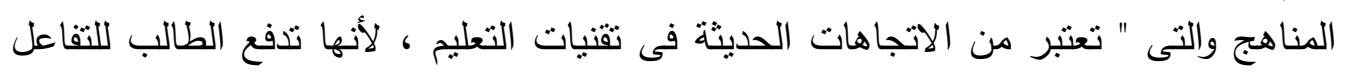

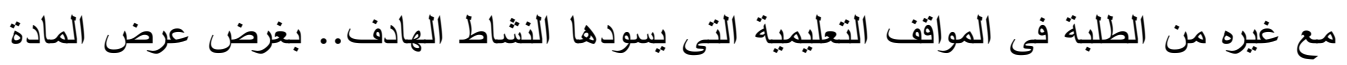

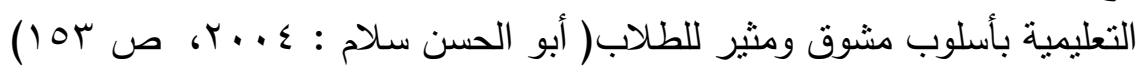

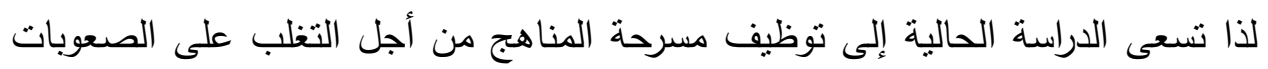

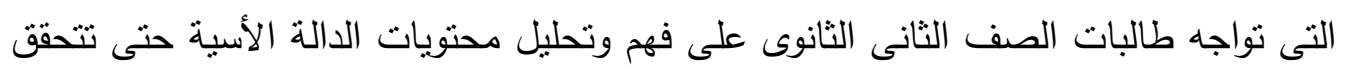

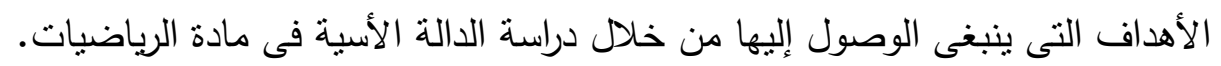

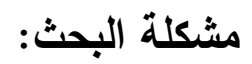

لاحظت الباحثة من خلال قيامها بالإثراف على طلاب التربية الميدانية أن نشاط مسرحة

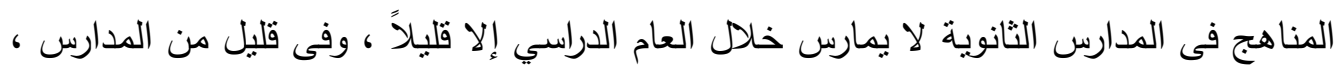

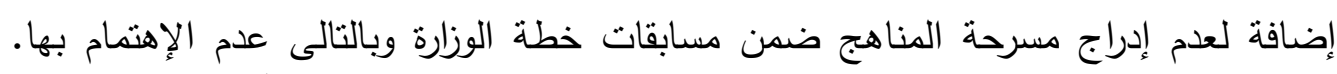

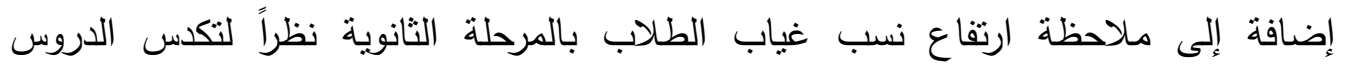

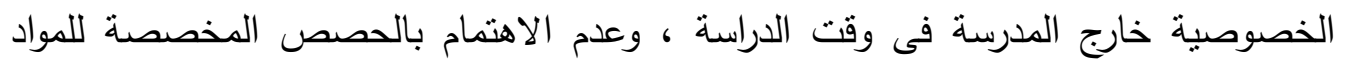

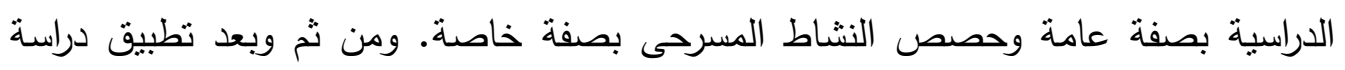
إسنطلاعية جاءت مؤكدة على عدم تفعيل مسرحة المناهج فى هذه المرحلة وأن معظم مدرسي

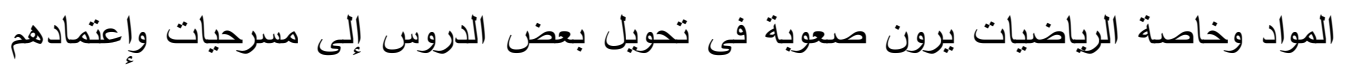

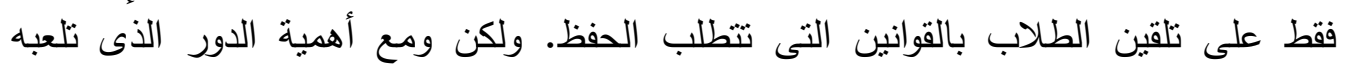

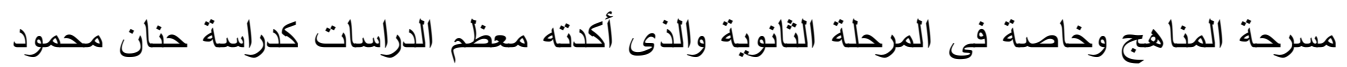

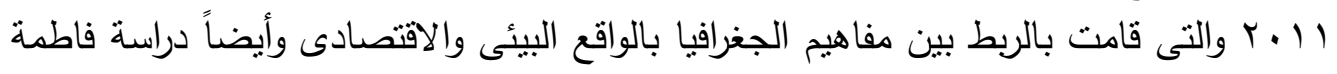

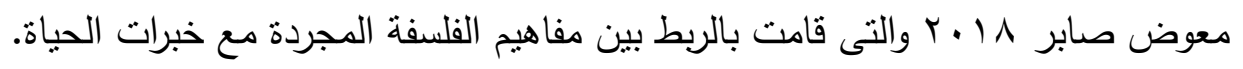

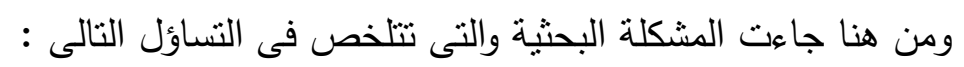

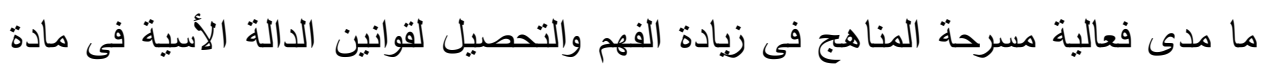

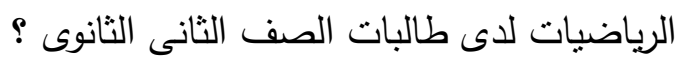


وينبيثق من هذا التساؤل عدة تساؤلات فرعية منها:

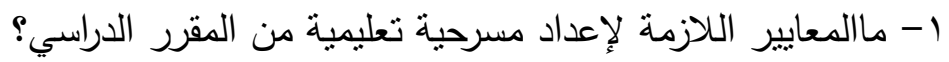

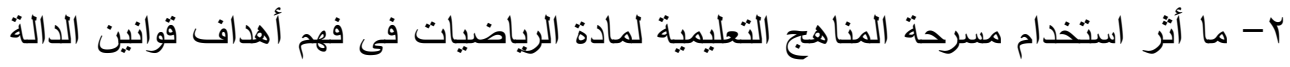

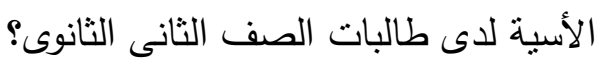

أهمية البحث

1- التغلب على الصعوبات التى تواجه طالبات الصف الثانى الثانوى لفهم مادة

$$
\text { الرياضيات. }
$$

ץ- زيادة إقبال طالبات المرحلة الثانوية على الانتظام فى الحضور داخل المدرسة وتفعيل دور الأنشطة وخاصة المسرح ، وضرورة الاستفادة منه فى العملية التعليمية.

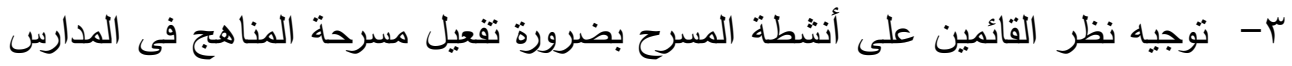
الثانوية ، وإدراجها ضمن مسابقات الوزارة.

أهداف البحث

ا- - معرفة أثر مسرحة وحدة الدالة الأسية فى تحصيل وفهم طالبات الصف الثانى الثانوى لأهداف قوانين الدالة الأسية فى مادة الرياضيات.

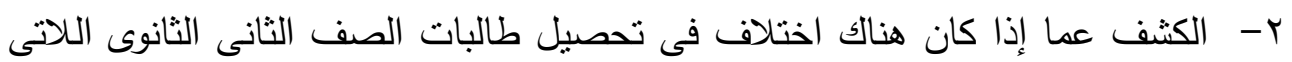
درسن بالطريقة النقليدية وتحصيل الطالبات اللاتى درسن بمسرحة المناهج.

\section{منهج البحث}

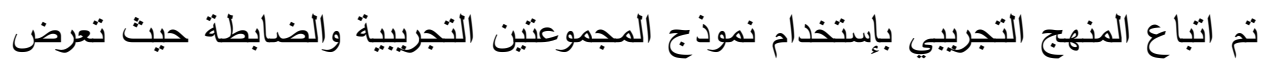

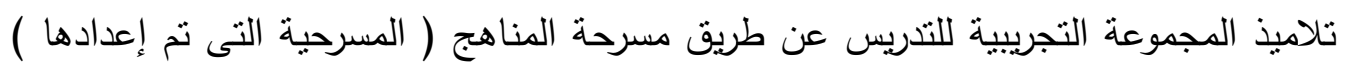

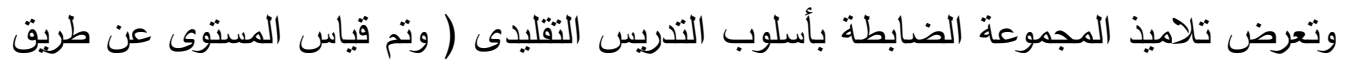

$$
\text { عينة البحث التحصيلى الذى تم إعداده) }
$$

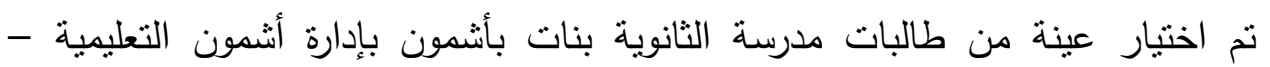

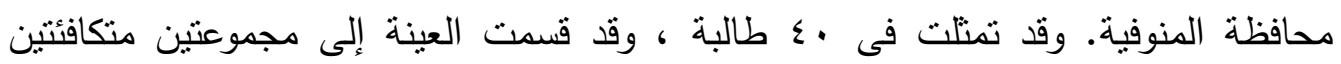

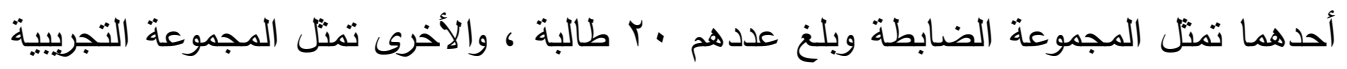

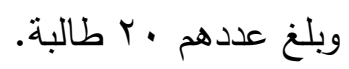
أدوات البحث

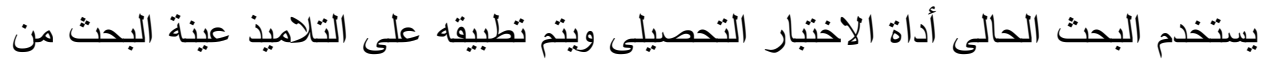

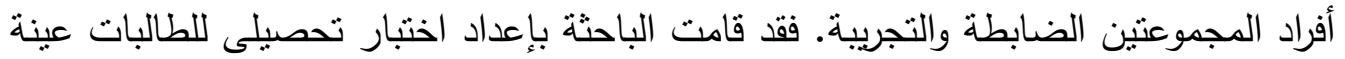

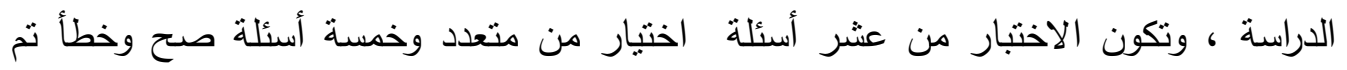

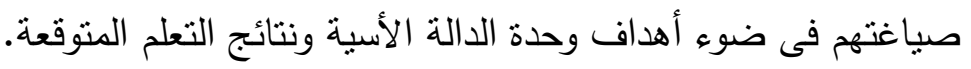




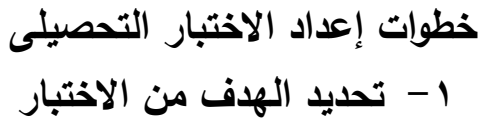

تم تحديد الهُف من الاختبار وهو الكثف عما إذا كان هناك اختلاف فى تحصيل

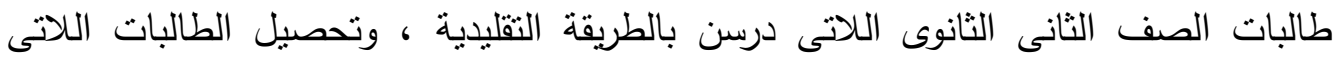

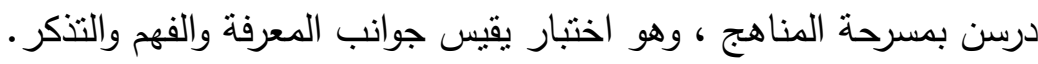
r - تحديد محتوى الاختبار

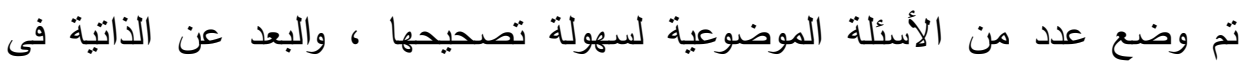
التصحيح ، كما أنها تمتاز بالثبات من خلد تحديد الإجابة بنقطة واحدة لا أكثر وشملت:

$$
\begin{aligned}
& \text { أولا: الاختبار من متعدد } \\
& \text { ثانياً: أسئلة الصح والخطأ } \\
& \text { r- إعداد جدول مواصفات }
\end{aligned}
$$

والهدف منه هو التأكد من أن الاختبار يقيس الأهداف المراد تحقيقها ، وللتأكد من ذلك تم عرض الاختبار على مجموعة من معلمى الرياضيات للصف الثانى الثانوى ، وذللك الإبداء

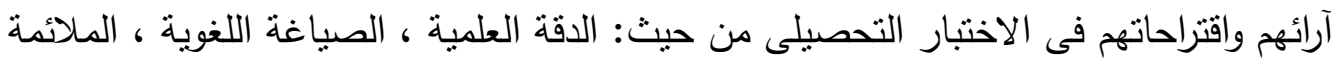
للطالبات ، تعليمات الاختبار ، تقدير الدرجات للأسئلة والفقرات. وطبق الأنه الاختبار على على عينة اسنطلاعية وتم حساب الثبات النصفى لفقرات الاختبار بعد تقسيمه إلى نصفين متكافئين فكان ا9. . وتم إعادة تطبيق الاختبار على العينة نفسها بعد أسبوعين فكان الثبات 97 . . . وهو ثبات مرتفع.

؛ - تقدير الارجات وطريقة التصحيح

قامت الباحثة بعمل نموذج للإجابة ليتم التصحيح على أساس هذا النموذج ولئ ، كما تم وضع

$$
\text { تثقسم حدود البحثة لكل سؤال. }
$$

حدود موضوعية : تثمنل فى وحدة الدالة الأسية في الرياضيات للصف الثانى الثانوى.

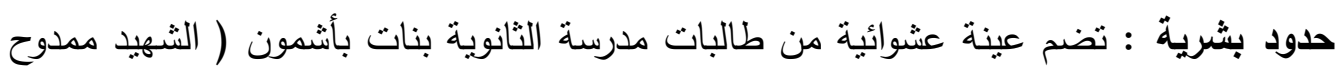

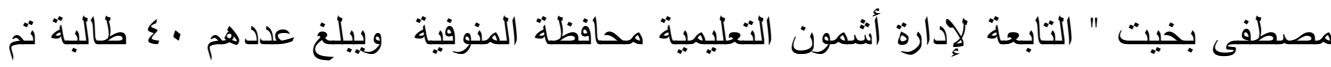

تقسيمهم إلى • r طالبة تمثل المجموعة الضابطة ، . r طالبة تمثل المجموعة التجريبية .

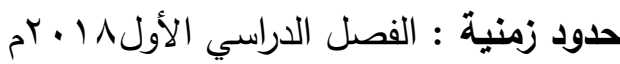

$$
\begin{aligned}
& \text { مبررات البحث }
\end{aligned}
$$

1- عدم تفعيل وإدراج مسرحة المناهج ضمن مسابقات خطة الوزارة وبالتالى أصبح لا يوجد

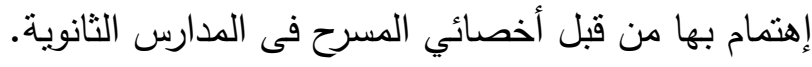


r- بعد إثبات فعالية مسرحة المناهج كوسيلة تعليمية تدريسية ، فكان ذلك دافعاً إلى تفعيل

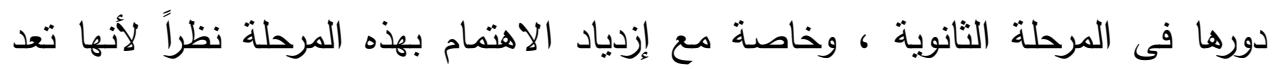
الطالب للمرحلة الجامعية. r- عدم اهنمام أى من الدراسات السابقة بنطبيق مسرحة المناهج لمادة الرياضيات للمرحلة الثانوية ، والتى تتتاول الكثثر من القوانين والمفاهيم المجردة التى تتطلب من الطالب فهيها

$$
\text { مصطلحات البحثها. }
$$

هناك العديد من التعريفات لمسرحة المناهج ، كما أن لها مرادفات كثثرة منها الخبرة

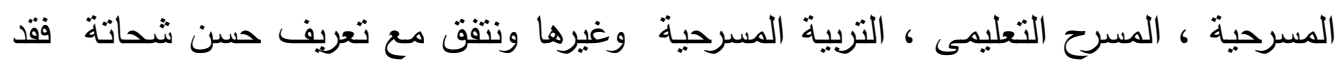

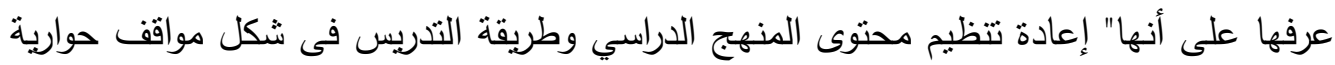

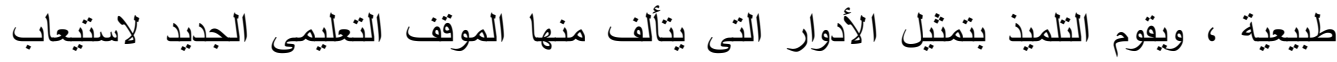

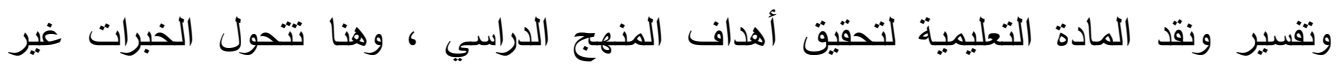

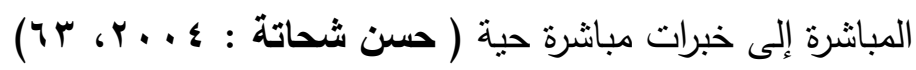

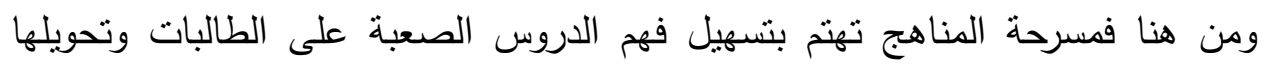

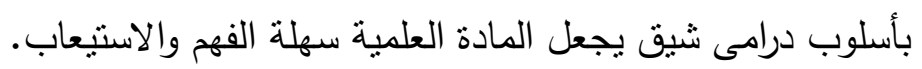

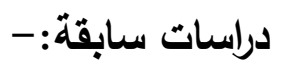

1- دراسة : فاطمة معوض صابر بعنوان " فاعلية استخدام المدخل المسرحى فى تنمية

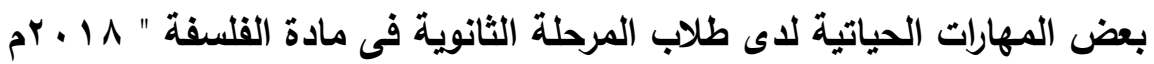

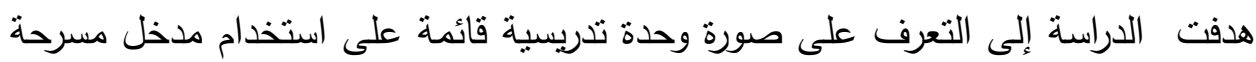

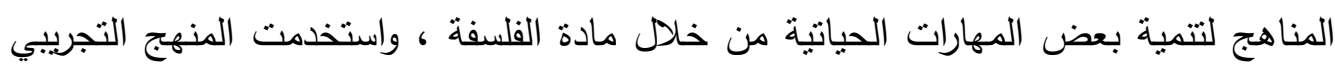
وقامت بالتطبيق على عينة عشوائية من طلاب الصف الأول الثانوى بمحافظة بنى سويف.

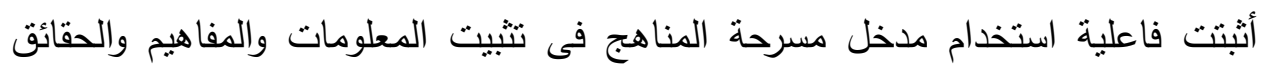
لمادة الفلسفة بالمقارنة بالطرق التقليدية المستخدمة.

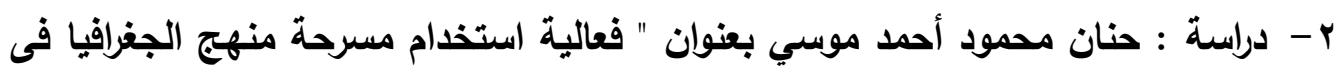

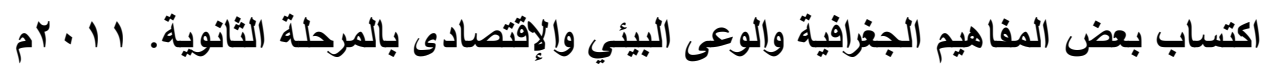
هدفت هذه الدراسة إلى توضيح دور فعالية مسرحة المناهج فى إكساب تلاميذ المرحلة والئل

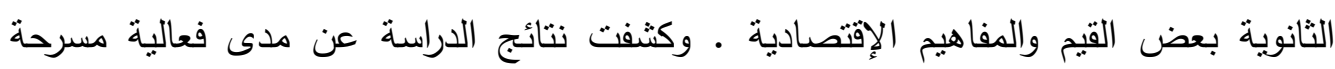

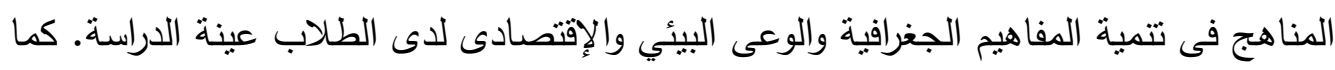

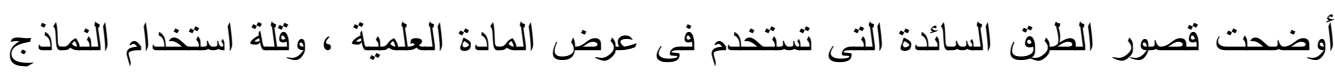

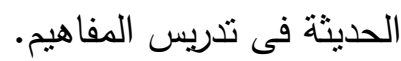


r- - دراسة : سامع إبراهيم عوض الله بعنوان " أثر مسرحة منهج القلسفة على تنمية القيم

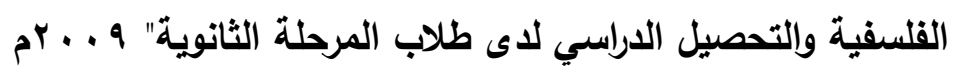

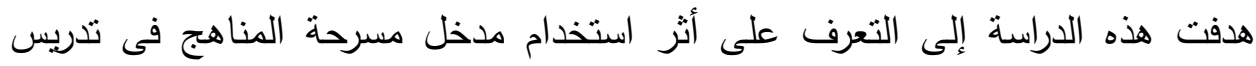

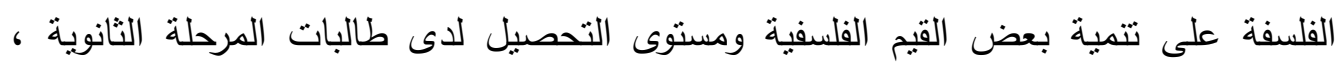
وأيضاً الكثف عن العلاقة بين تتمية القيم الفلسفية بإستخدام مدخل الفلسفة ومستوى التحصيل الدراسى لدى طالبات المرحلة الثانوية. واستخدم الباحث المنهج الوصفى فئه فئى الدراسة النظرية والمنهج التجريبي فى الدراسة الميدانية.

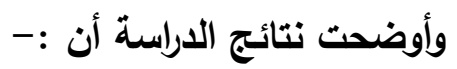

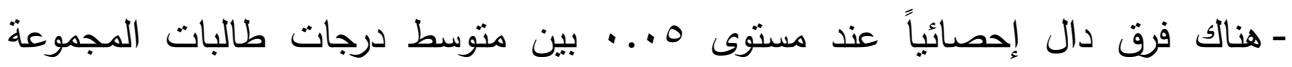
الضابطة اللاتى درسن الفلسفة بالطريقة التقليدية ومتوسط درجات طالبات المجموعة التجريبية اللاتى درسن الفلسفة باستخدام مدخل مسرحة المناهج على مقياس القيم الفلسفية

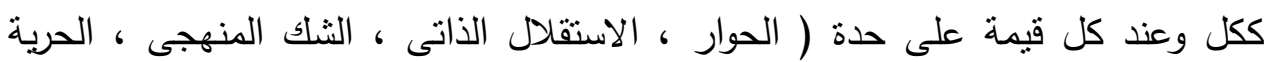
الإنسانية ، التسامح الفكرى ، التفكير الناقد ) لصالح المجموعة التهار ، التجريبية. التعليق على الاراسات السابقة ، الإنح الفكرية

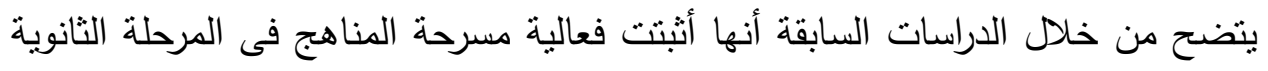

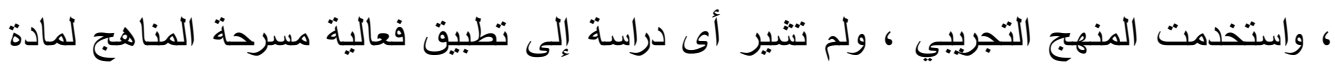

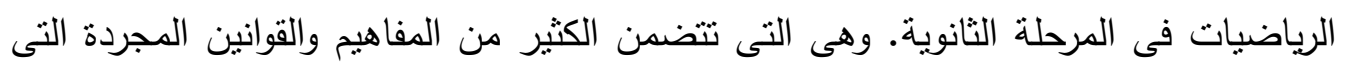
يصعب على الطلاب فهمها دون الربط بواقع الحياة وهو مايحدث عن طريق استخدام مسرحة المناهج.

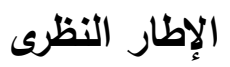
مسرحة المناهج

نعنى بها استخدام المسرح في عرض المناهج التعليمية وتيسير سهولة فهمها بطريقة جذابة وممتعة. ( جمال محمد النواصرة : ص وبى) ومسرحة المناهج لا تكتفى على منهج

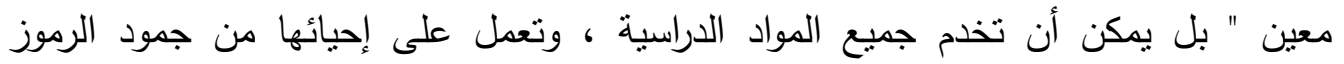

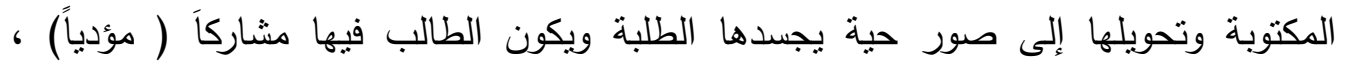
ومشاهداً ( متلقياً ) ويمكن أن تخدم هذه الفكرة جميع فئات المتعلمين(جمال محمد النواصرة

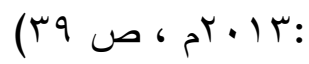

وترى الباحثة أن مسرحة المناهج هى تحويل درس أو أكثر من المنهج الدراسى بصورة

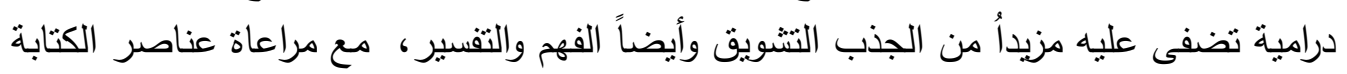
وعناصر الإخراج. 


\section{أهمية مسرحة المناهج في المرحلة الثانوية}

الطالب في هذه المرحلة يكون قد اكتمل نموه العقلى والفكرى والوجدانى ، ولكنه يحاول

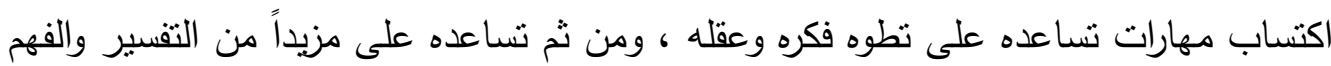

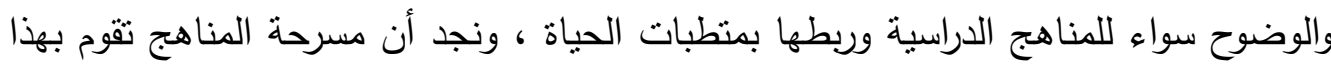

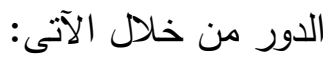

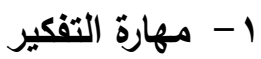

إن التحصيل الدراسي يرتبط ارتباطاً وثثقاً بإكتساب الطلبة مهارات التفكير ، فبعض

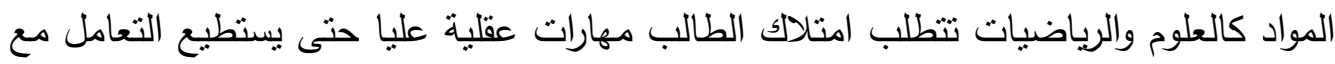
متطلبات هذه المواد فيما يتعلق بالقوانين ( pogrow,2009)

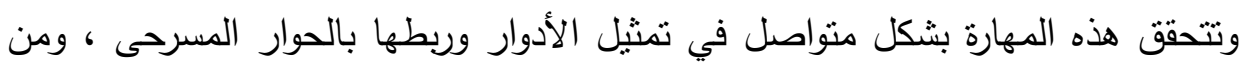

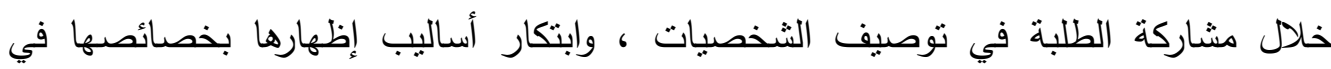

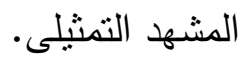
r - مهارات البحث والاستقصاء

تعد الدراما مدخلاً مناسباً للحد من ظاهرة التعلم السلبي إذاء نقلت الإهتمام من المعلم إلى الى

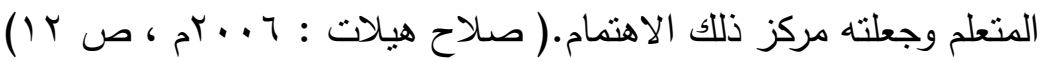
وبالتالى نجد أن مسرحة المناهج تعمل على دلى بناء تعلم ذاتى للمتعلم ليقوم بالبحث

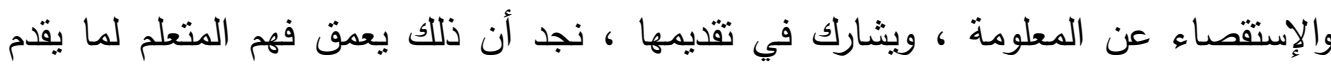

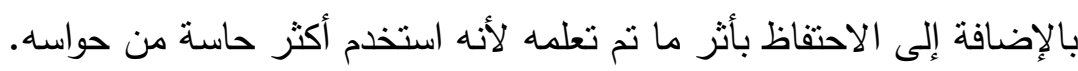

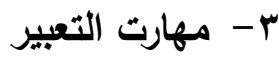
من خلال ما توفره مسرحة المناهج من مواقف يتم من خلالها إتاحة الفرصة للطلاب

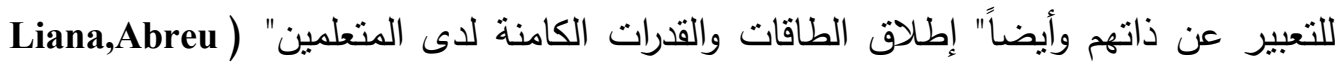
(2013 p115 צ - - مهارات العمل الجماعى تتحقق هذه المهارة من خلال التعاون الذى يتسم به العمل المسرحى ، ولا يتم في

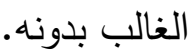

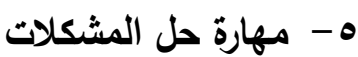
قد تكون هذه المهارة أكثر تعقيداً وتقدماً فمن خلالها يكون الطلبة لهم قدرة التصرف عند

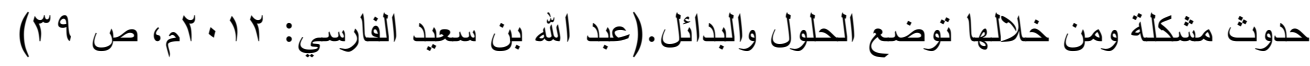




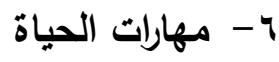

مسرحة المناهج لها القدرة في جعل المتعلم يمارس ما يقدم من واقع الحياه ، فعندما ينت مسرحة درس معين وخاصة دروس الرياضيات يتم ربطها بواقع الحياة عن طريق أخذ خبرة

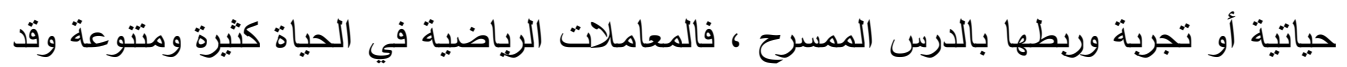

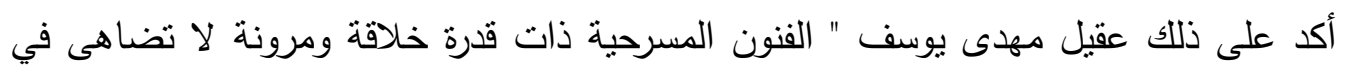

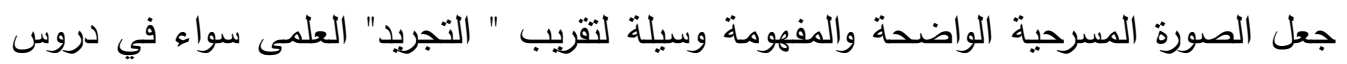

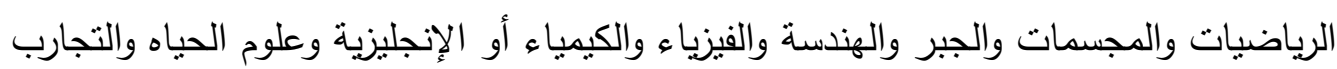

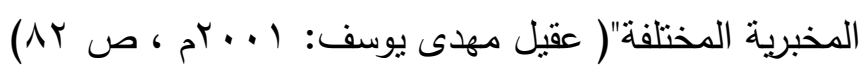
مرحلة كتابة النص النص

ا-إيجاد الدرس الذى يمثل صعوبة بالنسبة للتلاميذ ، ومصادر الحصول على ذلك تمثل في

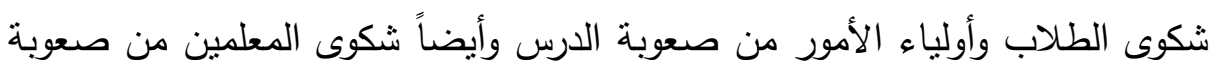
توصيل المعلومة للطالب.

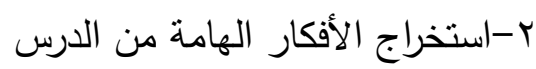

r-التزود بالمعلومات الكافية التى من شأنها أن تضيف للإس الدرس ما لا يستطيع المعلم داخل الفصل أن يقوله. צ-وضع خطة لكتابة المسرحية وتتمل وضع إطار حياتى ينم من خلاله تجسيد الدرس في

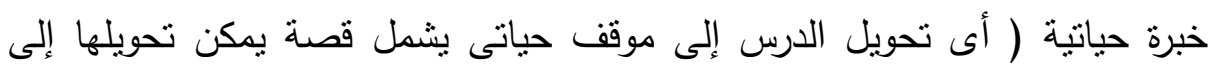

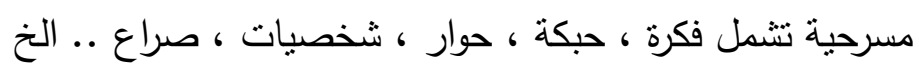
ه-يراعى الآتى عند كتابة المسرحية: أ- يجب أن تكون جيدة البناء ، لها بداية منماسكة واضحة ، ولئهة ، ويتصاعد الحدث بها

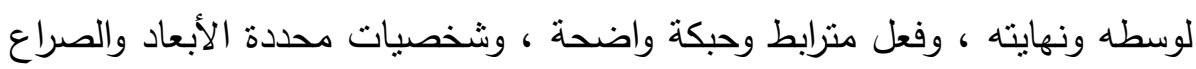

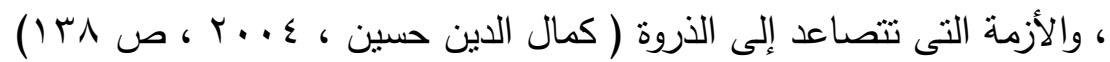

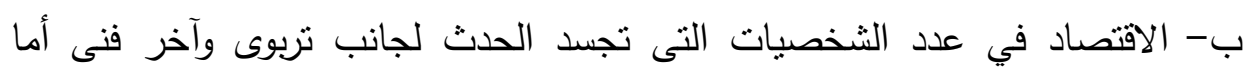
التربوى فيرجع إلى قدرة التلاميذ على الانتباه والتركيز ، والفنى لقلة عدد العاملين في تُدي

$$
\text { منل هذه الفرق. }
$$

\section{أسس إعداد النص المنهجى هذه المرف}

1- أن تكون المسرحية جزءاً من البرنامج التعليمى أو المقرر الدراسي.

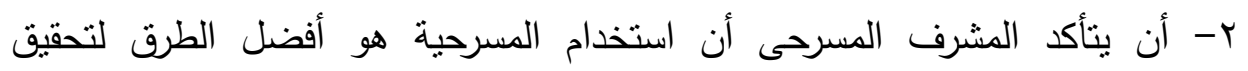
الأهداف وهو توصيل المادة التعليمية. 
r- أن يكون المشرف على دراية كافية بموضوع المسرحية وقواعد إخراجها وأسسه

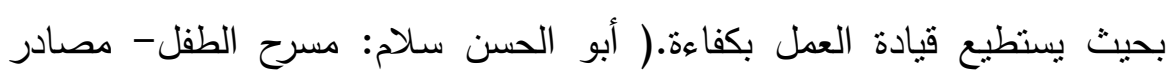

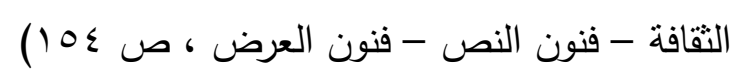

وهذه بمثابة إرشادات لابد من مراعاتها ووضعها في الاعتبار عند إعداد مسرحية تعليمية.

\section{مرحلة إخراج المسرحية التعليمية}

ا- توزيع نسخ المسرحية على الطالبات وتوضيح بعض الأهداف وذلك من خلال تدريبات

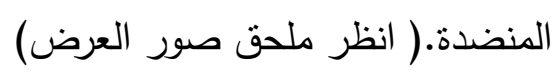

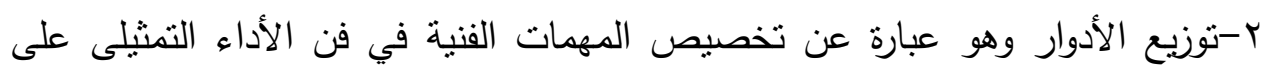
الفرقة المسرحية مختلفة الأنماط والثخصيات. لكى يتم بعد عملية ( توزيع الأدوار)

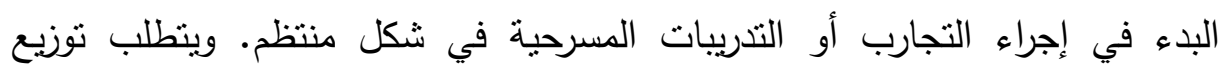

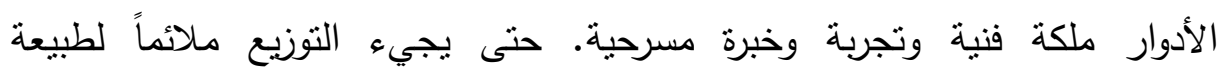

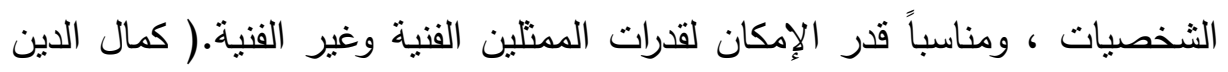

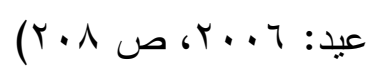

r-وضع خطة إخراجية للنص بالأسلوب الملحمى وشمل استخدام أثاث الفصل المقعد

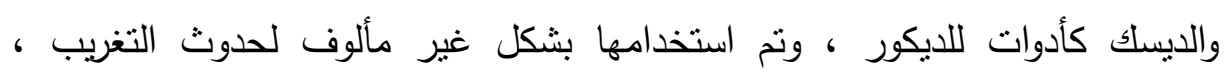

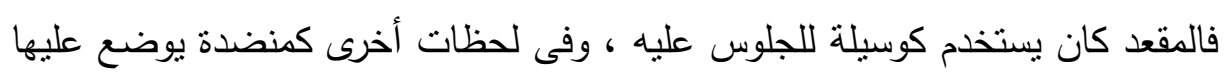

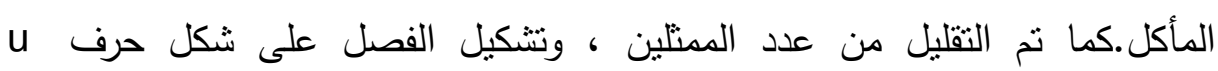
واستغلال مقدمة الفصل كمكان للمشاهدة أما مقاعد التلاميذ كأماكن لجلوس التلاميذ عندي

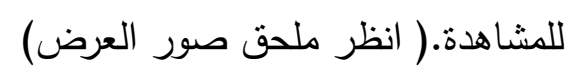

ع-تم مراعاة زمن العرض الذى لم يتجاوز زمن الحصة المتاح ، وهو شرط من شروط مأم

$$
\text { نجاح مسرحة المناهج داخل الفصل. }
$$

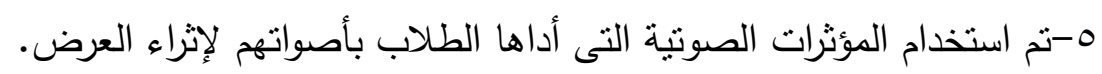

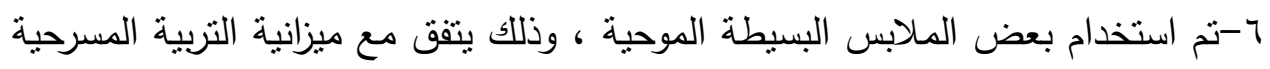

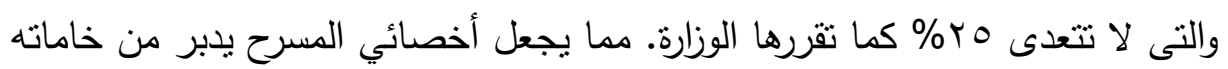

وبستخدم البدائل لإخراج عرض ناجح. 


\section{عرض نتائج البحث \\ أولاً: تجانس المجموعات.}

ثانيًا: عرض النتائج الخاصة بفروض المرض البحث.

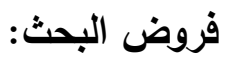

1. لا يوجد فرق دال إحصائيًا عند مستوى دلالة ه... بين متوسطى درجات المجموعة

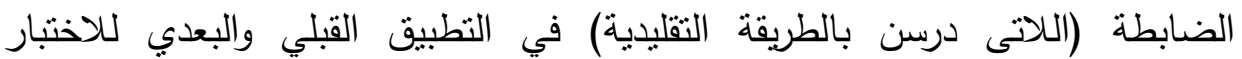

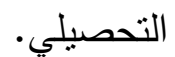
r.يوجد فرق دال إحصائًا عند مستوى دلالة ه... بين متوسطى درجات المجموعة

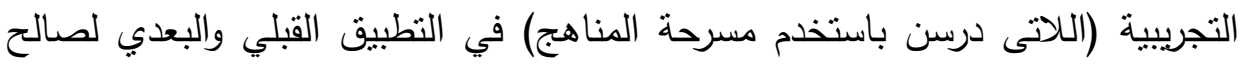
التطبيق البعدي.

r. يوجد فرق دال إحصائيًا عند مستوى دلالة هـ ـ. . بين متوسطى درجات المجموعتين

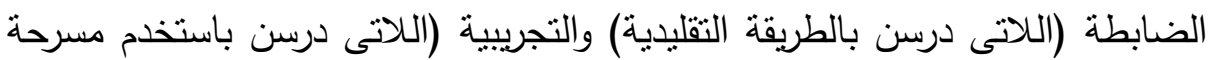

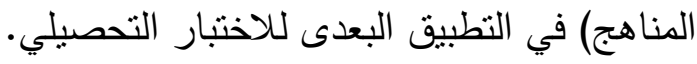

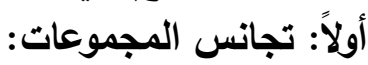

لحساب تجانس مجموعات البحث قامت الباحثه بالتطبيق القبلي لأداه البحث المتمثلة في

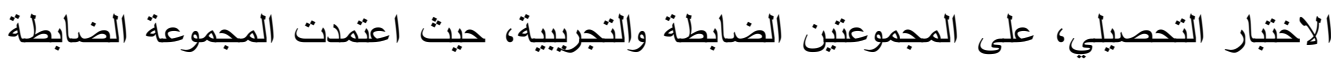

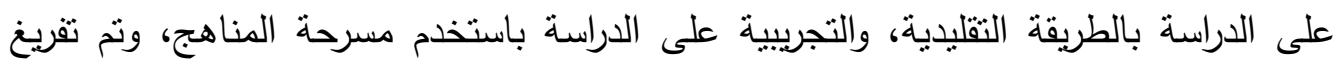

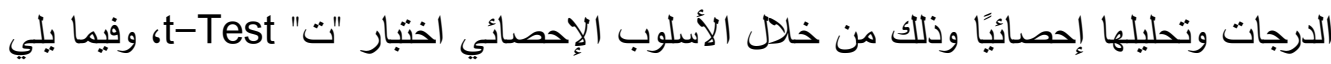

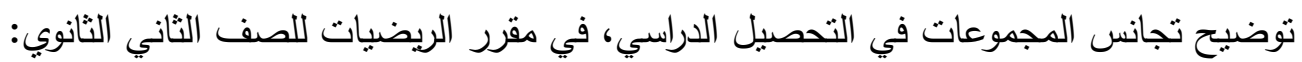
1 - تجانس مجموعات البحث فيما يتعلق بالتحصيل الدراسي:

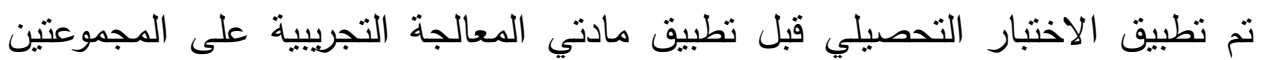
الضابطة والتجريبية، ثم حساب الفروق بين المجموعنين باستخدام اختبار "ت"، كما هو موضح

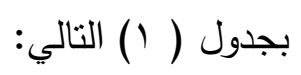

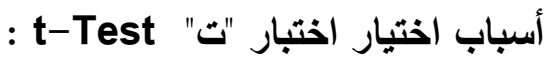

1. التوزيع الإعتدالي لدرجات الطلاب للمجموعتين التجريبيتين في التطبيق القبلي

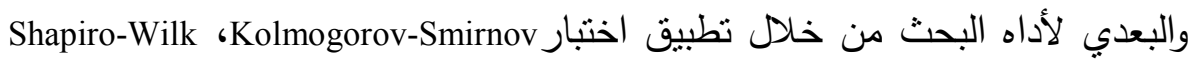

$$
\text { لاختبار التوزيع الاعتدالي. }
$$

r r. عشوائية العينات في المجموعتين التجريبيتين وذللك من حيث اختيار أفراد كل عينة

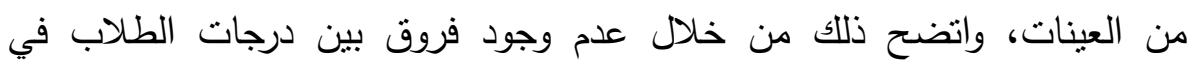

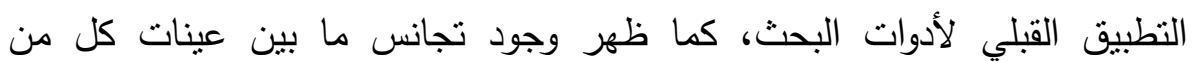

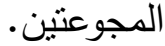


r. تساوى التباين بين مجموعات البحث وفقًا لاختبار لفين Levene's test.

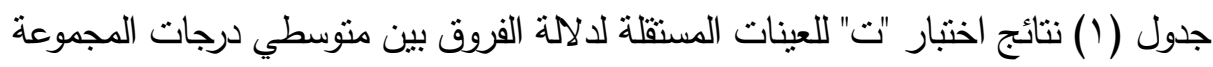

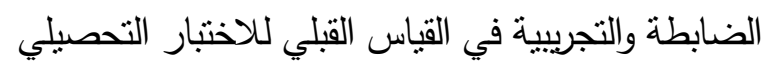

\begin{tabular}{|c|c|c|c|c|c|c|c|}
\hline الدلالة & درجات & قيمة "ت & الفرق بين & الانحراف المعياري & المتوسط & العينة & المجموعة \\
\hline \multirow{2}{*}{$.7 \leqslant V$} & \multirow{2}{*}{ MA } & \multirow{2}{*}{$\cdot . \leqslant T r$} & \multirow{2}{*}{.70.} & $r .99$ & 10.9. & $r$. & ضابطة \\
\hline & & & & $\varepsilon . \wedge 7$ & 10.50 & $r$. & تجريبية \\
\hline
\end{tabular}

يتضح من خلال جدول (1 ) أن متوسط درجات طلاب المجموعة الضابطة في التطبيق

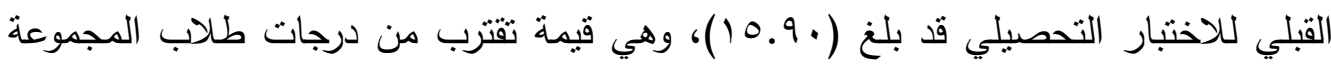

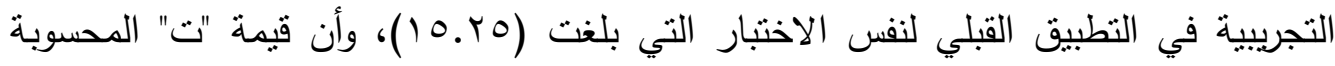

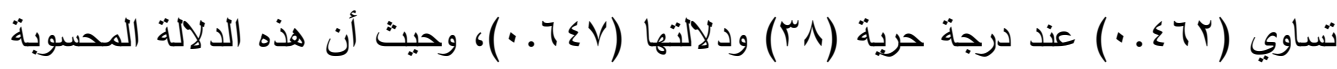

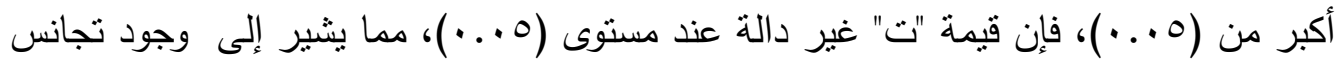
بين المجموعتين الضابطة والتجريبية إلى أقصي حد مدكن في التحصيل التهي الدراسي.

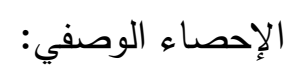
يعرض جدول ( r ب) قيم المتوسط والانحراف المعياري لدرجات طلاب المجموعة الضابطة

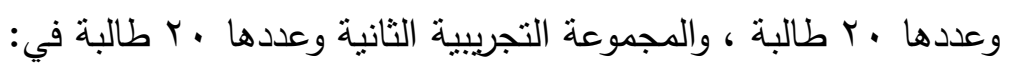
O التطبيق القبلي والبعدي لاختبار التحصيل الدراسي في المجموعة الضابطة. م التطبيق القبلي والبعدي لاختبار التحصيل الدراسي للمجموعة التجريبية.

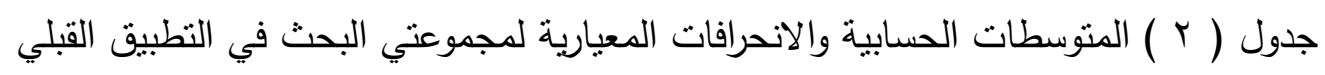
والبعدي لأدوات البحث

المجموعة / الأدوات

المجموعة الضابطة (اللاتى درسن بالطريقة التقليدية)

\begin{tabular}{|c|c|c|c|}
\hline r.99 & 10.r. & $r$. & التطبيق القبلي للاختبار التحصيلي \\
\hline$\varepsilon . \wedge r$ & 10.9 & $r$. & التطبيق البعدي للاختبار التحصيلي \\
\hline
\end{tabular}

المجموعة التجريبية الثانية (نموذج الفصل المقلوب القائع على الفيديو والمزود بتلميح الصورة)

\begin{tabular}{|c|c|c|c|}
\hline$r . . \wedge$ & 10.10 & $r$. & التطبيق القبلي للاختبار التحصيلي \\
\hline$\varepsilon . \wedge 7$ & Yะ.T. & r. & التطبيق البعدي للاختبار التحصيلي \\
\hline
\end{tabular}


ثانيًا: عرض النتائج الخاصة بفروض البحث:

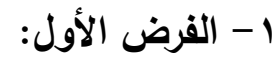

ينص الفرض الأول على أنه " لا يوجد فرق دال إحصائيًا عند مستوى دلالة ه ... بين

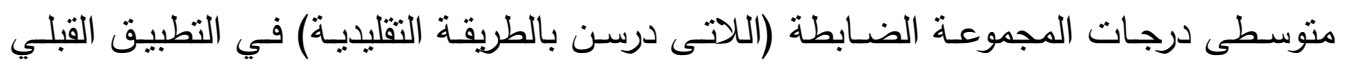
والبعدي للاختبار التحصيلي ".

للتحقق من صحة الفرض قامت الباحثه بتطبيق اختبار "ت" للعينات المرتبطة، وذلك من خلاد

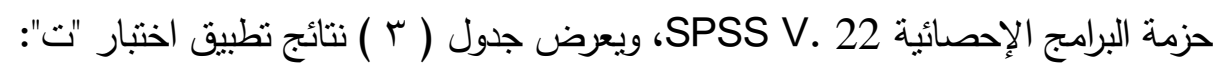

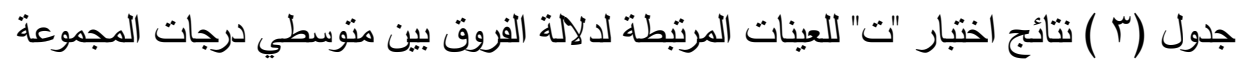

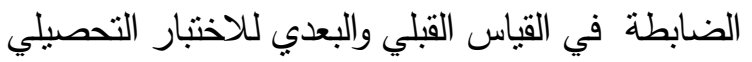

\begin{tabular}{|c|c|c|c|c|c|c|c|}
\hline مستوى الدلالة & درجات & قالمحة "ت" & الفرق بين & الانحراف & المتوسط & العينة & التطبيق \\
\hline \multirow{2}{*}{.0 Oro } & \multirow{2}{*}{19} & \multirow{2}{*}{$. \quad T \leq V$} & \multirow{2}{*}{$\because v \ldots$} & $r .99$ & 10.r. & \multirow{2}{*}{$r}$. & قبلي \\
\hline & & & & 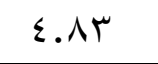 & 10.9. & & بعدي \\
\hline
\end{tabular}

يتضح من خلال جدول (r ) أن متوسط درجات طلاب المجموعة الضابطة في التطبيق

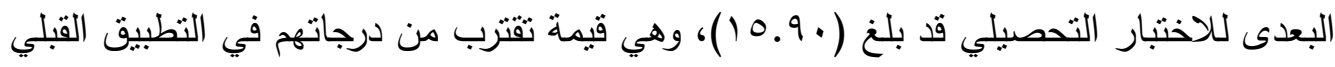

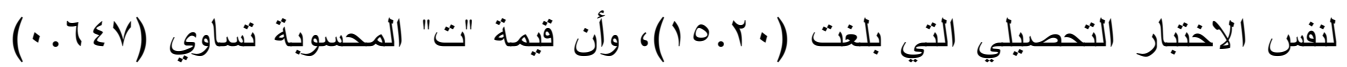

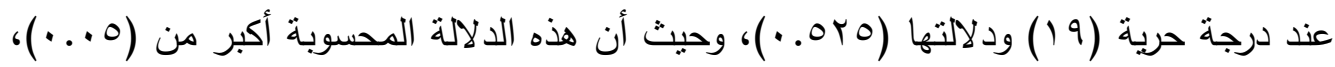

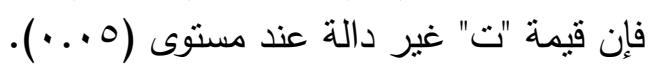

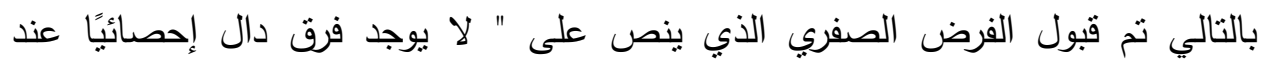
مستوى دلالة ه .. • بين منتوسطى درجات المجموعة الضابطة (الذين درسوا بالطريقة التقليدية)

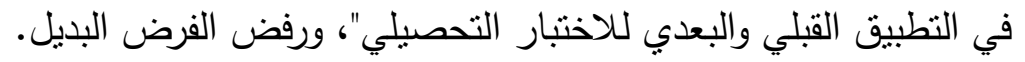

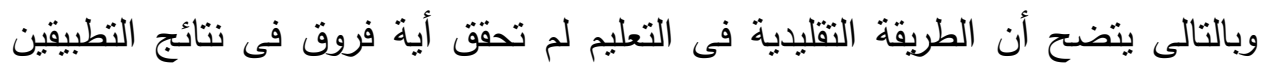

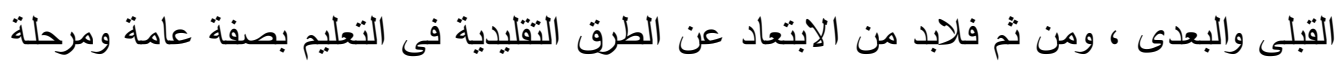

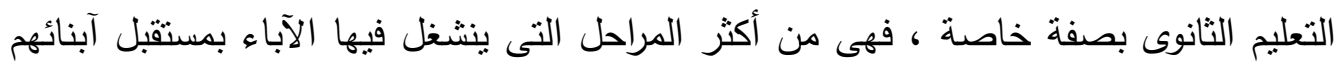

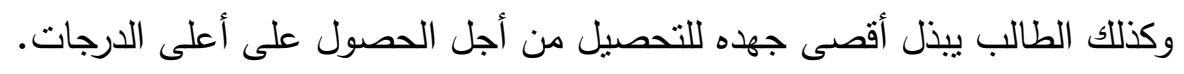

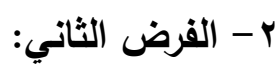

ينص الفرض الثاني على أنـه " يوجد فرق دال إحصـائيًا عند مستوى دلالـة ه ... بين

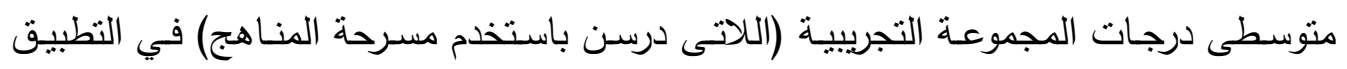
القبلي والبعدي لصالح النطبيق البعدي". 


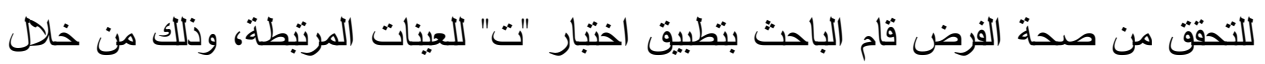

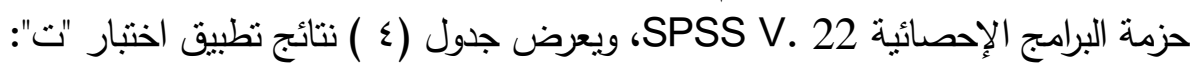

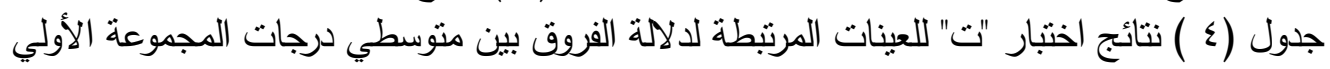

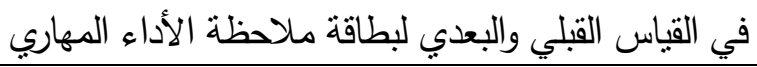

\begin{tabular}{|c|c|c|c|c|c|c|c|}
\hline مستوى الدلالة & الحربة & قالمحسوبة "ت & المتوسطين بين & الالحراف & المتوسط & العينة & التطبيق \\
\hline \multirow{2}{*}{$\cdots \cdots$} & \multirow{2}{*}{19} & \multirow{2}{*}{$7 . \% 9 \leq-$} & \multirow{2}{*}{9.10} & $\varepsilon . \wedge \uparrow 0$ & 10.10 & \multirow{2}{*}{$r}$. & قبلي \\
\hline & & & & r...人o & $r \leqslant .7$. & & بعدي \\
\hline
\end{tabular}

يتضح من خلال جدول ( ؟ ) أن متوسط درجات طلاب المجموعة التجربيية في التطبيق

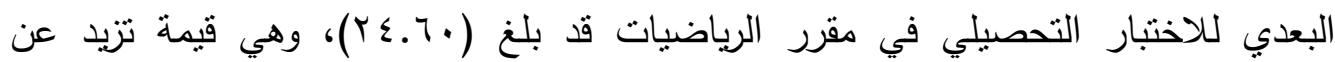

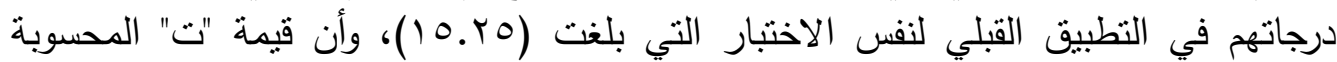

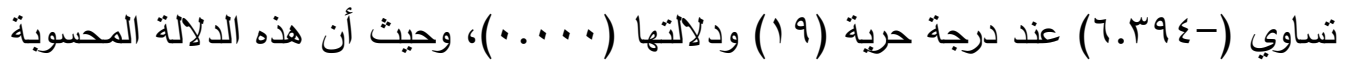

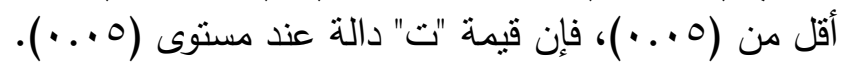

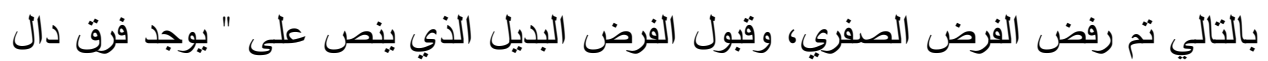

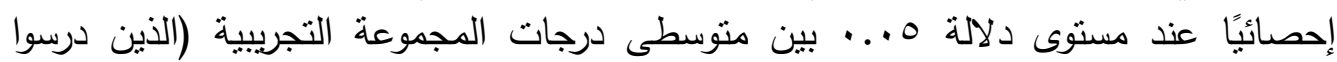

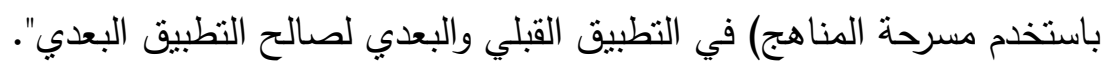

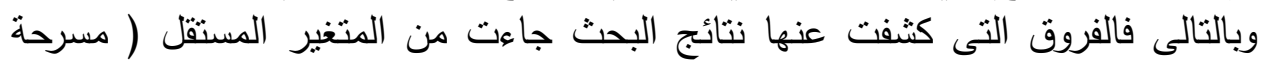

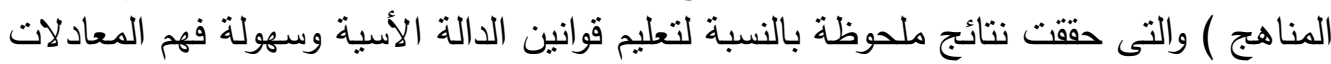

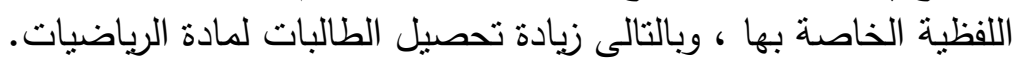
r- الفرض الثالث:

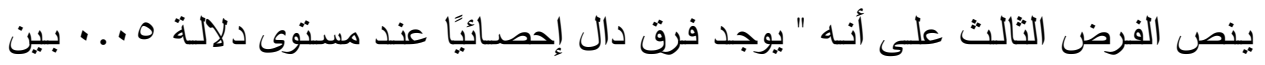

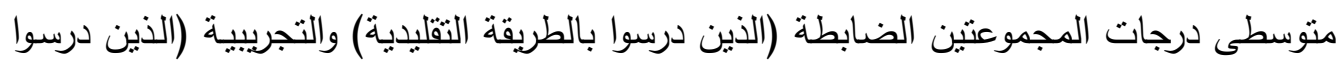

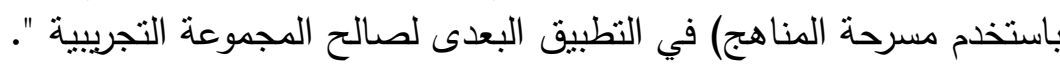

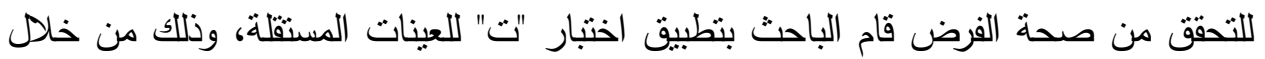

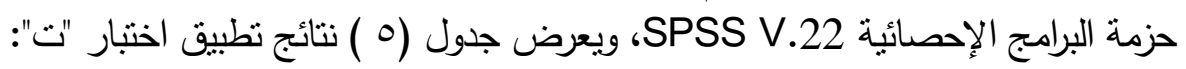

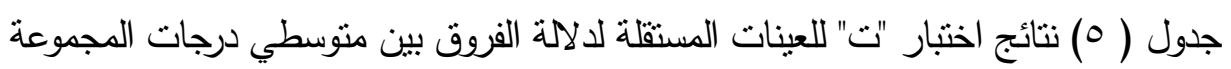

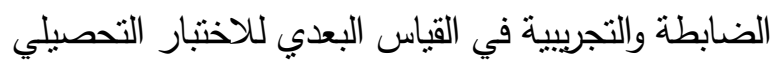

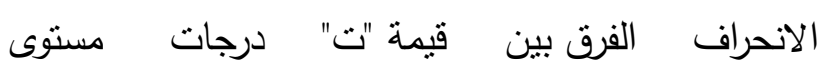

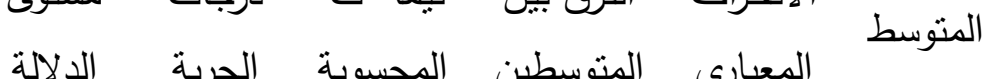
\begin{tabular}{llllllll} 
الضابطة & & \\
\hline
\end{tabular} 
يتضح من خلال جدول (0) أن متوسط درجات طلاب المجموعة التجريبية في التطبيق

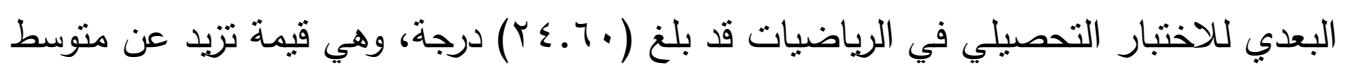

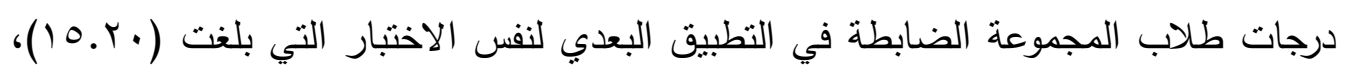

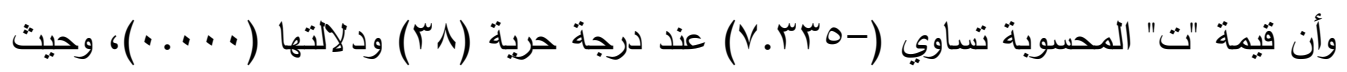

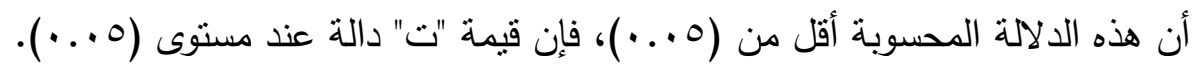

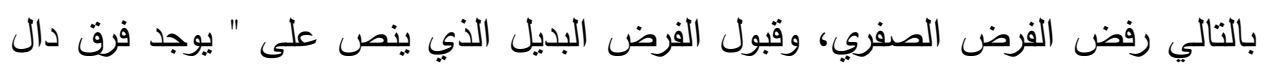

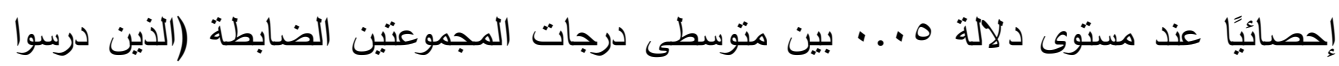
بالطريقة التقليدية) والتجريبية (الذين درسوا باستخدم مسرحة المناهج) في التطبيق البعدى دئي لصالح المجموعة التجربيية".

وبالتالى يثير ذلك إلى زيادة الفهم والتحصيل لدى الطالبات التى درسن بمسرحة المناهج

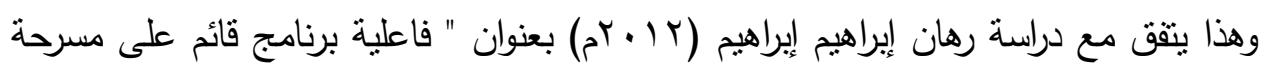

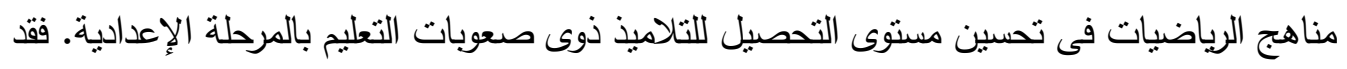
كثفت نتائج الدراسة على وجود فروق ذات دلالة إحصائية بين متوسطى درجات تلاميذ المجموعتين

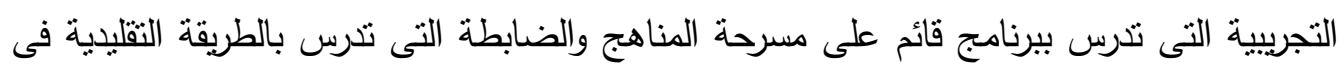
التطبيق البعدى.

ومن خلال ماسبق نجد أنه ثبت بالتجربة مدى فاعلية مسرحة المناهج فى فهم المعادلات

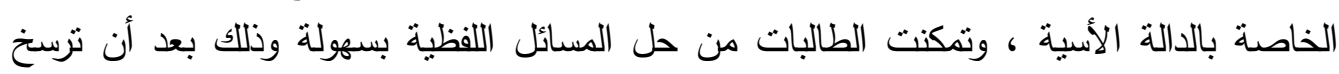

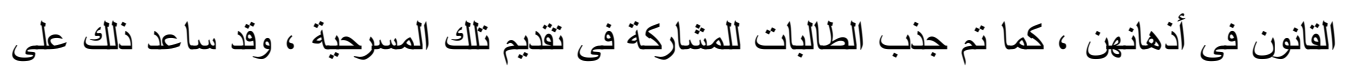

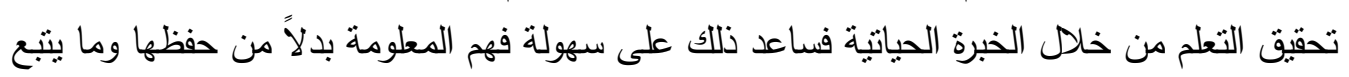
ذللك بعطية النسيات النى تتزتب على الحفظ دون فهم. نتائج الاراسة

يوجد فرق دال إحصائياً بين متوسطى درجات المجموعة التجريبية ( اللاتى درسن

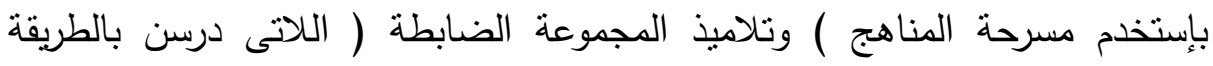
التقليدية ) فى القياس البعدى للاختبار التحصيلى لصالح تلاميذ المجموعة التجريبية.

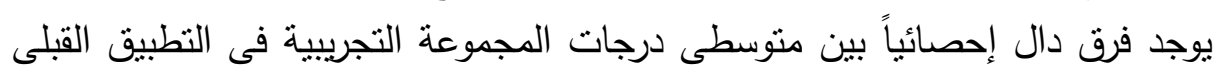

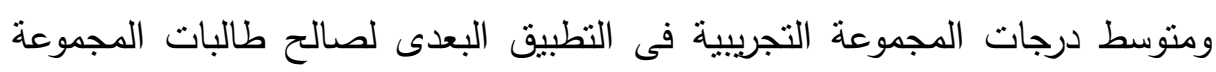

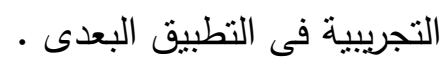

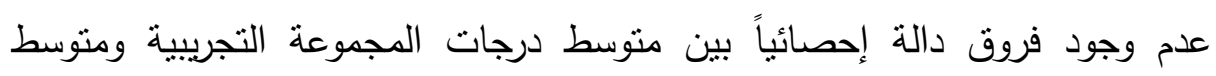

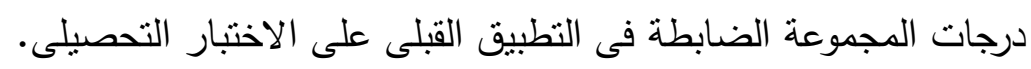


عدم وجود فروق دالة إحصائياً بين متوسط درجات الدموعة الضابطة فى التطبيق القبلى ومتوسط درجات المجموعة الضابطة فى التطبيق البعدى على لئى الاختبار التحصيلى. سرعة الفهم والاستيعاب لقوانين الرياضيات لدى الطالبات عينة الدراسة كان أسهل عن طريق عرض المسرحية بينما كان بصعب ذلك عن طريق الحفظ والتلقين. توصيات البحث

ا- أن تولى الوزارة اهنماماً بإدراج مسرحة المناهج فى المرحلة الثانوية ضمن خطة المسابقات التى تعقدها على مدار العام.

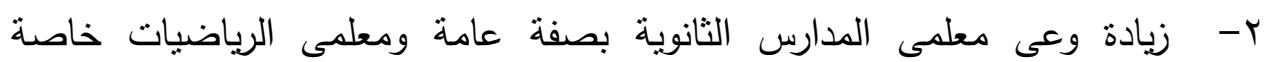
بضرورة استخدام مسرحة المناهج فى تدريس مادة الرياضيات.

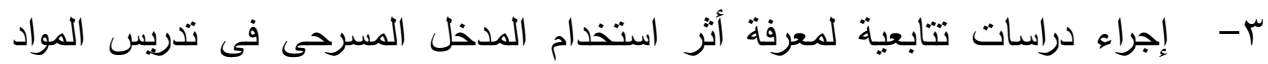
الدراسية لذوى الاحتباجات الخاصة بالمرحلة الثنانوية. 


\section{المراجع}

أولاً: الكتب أوب

ا-أبو الحسن سلام: مسرح الطفل - مصادر الثقافة - فنون النص - فنون العرض ( الإسكندرية ، دار

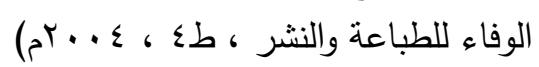

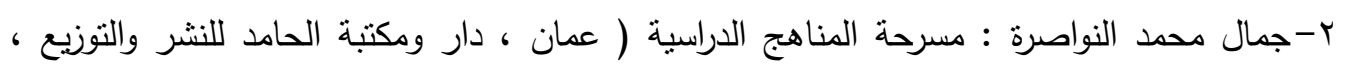

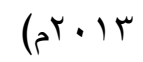

r-حسن شحاتة : أدب الطفل العربى ( القاهرة ، الدار المصرية اللبنانية ، طس ، ع . . זم) ع-صلاح هيلات : أثر التمثيل الدرامى للمادة التعليمية في تحصيل طلبة الصف الرابع في مبحث

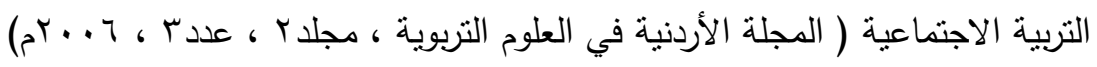
ه-عبد اله بن سعيد الفارسي : قيمة مسرحة المناهج وأهميتها للمعلم ، مجلة التطوير التربوى ، العدد

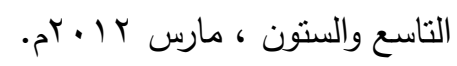

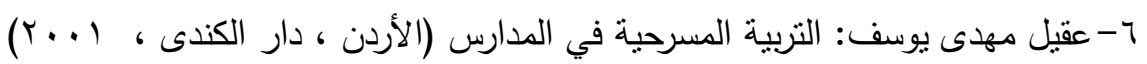

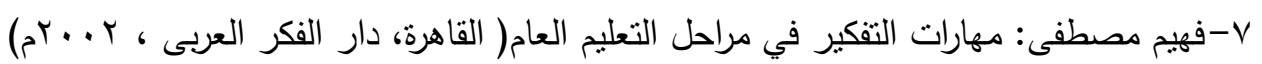

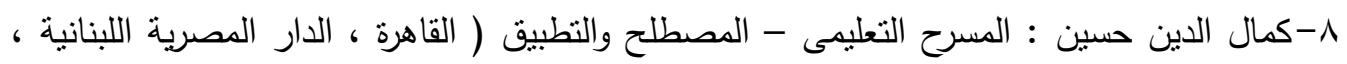
(a)

9-كمال الدين عيد: أعلام ومصطلحات المسرح الأوروبى ( الإسكندربة ، دار الوفاء لدنيا الطباعة

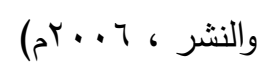

ثانياً:- الرسائل العلمية

- - حنان محمود أحمد موسي بعنوان " فعالية استخدام مسرحة منهج الجغرافيا فى اكتساب بعض

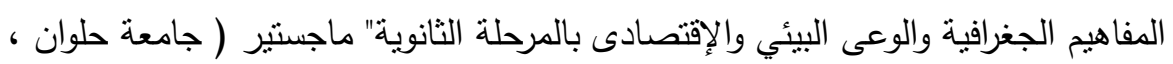

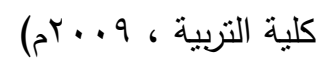

r- سامح إبراهيم عوض الله بعنوان " أثز مسرحة منهج الفلسفة على تتمية القيم الفلسفية والتحصبل الدراسي لدى طلاب المرحلة الثانوية" ماجسنير ( جامعة حلوان ، كلية التربية ، 9 ، . ب م) r- فاطمة معوض صابر بعنوان " فاعلية استخدام المدخل المسرحى فى تتمية بعض المهارات

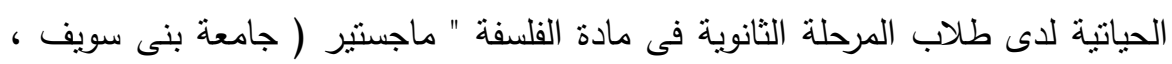

$$
\begin{aligned}
& \text { كلية التربية ، 1 ( • بم) } \\
& \text { ثالثاً:-- المراجع الأجنية }
\end{aligned}
$$

1- Liana,Abreu( 2013); thirty years of music and drama education in the madeira island facing future challenges, Research centre in psychology of music and education ( CIPEM). College of education, polytechnic Institute , Island.

2- Pogrow,s (2009) Teaching content outrageously. San Francisco: Jossey-Bass. 


\section{ملاحق البحث}

الملحق الأول:-الاختبار التحصيلي

تعليمات الاختبار

عزيزتى الطالبة لديك مجموعة من الأسئلة مقسمة إلى قسمين ، القسم الأول: أسئلة الاختيار

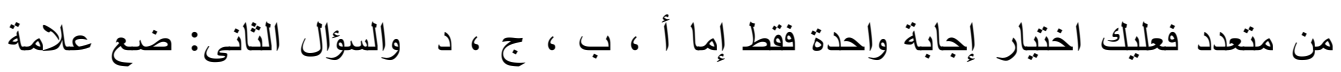
صح أو خطأ فعليك وضع علامة واحدة فقط ولاتتركى أى سؤال دون الإجابة عليه.

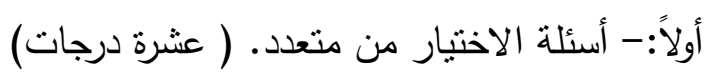

يقل عدد البكتريا نتيجة لإستخدام إحدى المعالجات الكيميائية ، وقد كان عدد البكتريا بعد

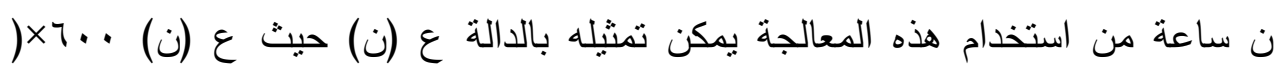

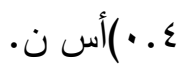

1- اكتب المعادلة التى يمكن استخدامها لحساب معدل التتاقص ( درجة)

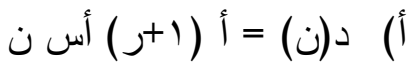

$$
\begin{aligned}
& \text { ب) د(ن) = أ (أر) أس ن أس أس }
\end{aligned}
$$

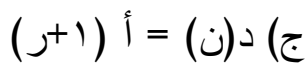

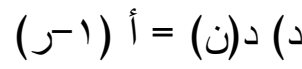

ץ- كم كان العدد عندما استخدمت المعالجة الكيميائية لأول مرة؟ ( درجة)

$$
\begin{aligned}
& \text { أ... } \\
& \text { ب } \\
& \text { ج) } \\
& 10 \ldots \text { ( }
\end{aligned}
$$

r- ما معدل تتاقص عدد البكتريا ( درجة)

$$
\begin{aligned}
& \text { أ) ، ب\% في الساعة } \\
& \text { ب) ז\% بـ الساعة }
\end{aligned}
$$

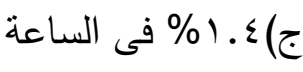

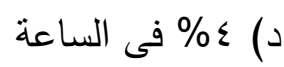


- يزداد عدد الأشخاص المصابين بأحد الفيروسات بمعدل VIV فى السنة. فى العام الماضي . .

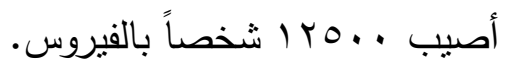

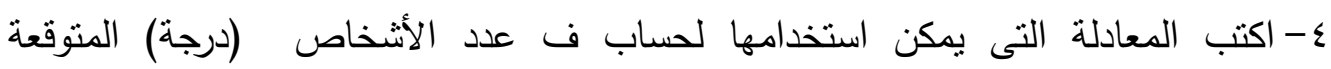

$$
\begin{aligned}
& \text { إصابتهم بالفيروس خلال ش أشهر قادمة. }
\end{aligned}
$$

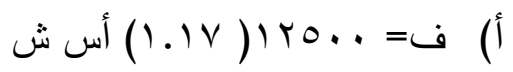

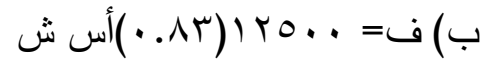

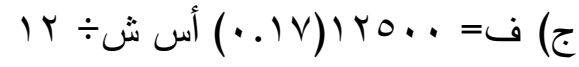

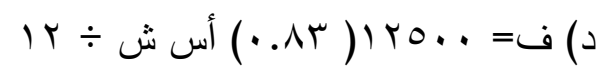

ه- كم شخص متوقعة إصابتهم بالفيروس خلا الأشهر السبعة القادمة؟ ( درجة)

$$
\begin{aligned}
& \text { أ } \\
& \text { ب) } \\
& \text { ج ( } \\
& \text { د) . (14. }
\end{aligned}
$$

- يتكاثر كائن حى دقيق بالانشطار الثنائي ، حيث تتشطر كل خلية إلى خليتين كل ساعة. إذا

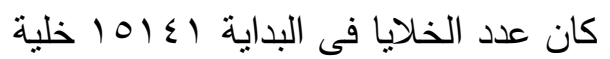

$$
\begin{aligned}
& \text { צ- عدد الخلايا بعد مرور ه ساعات. ( درجة) }
\end{aligned}
$$

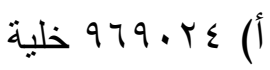

$$
\begin{aligned}
& \text { ب) · ( ) } \\
& \text { ج) }
\end{aligned}
$$

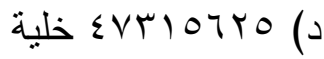

- Vتخفض قيمة سيارة مستععلة بمعدل ؟1\% سنوياً إذا كان سعر السيارة عند شرائها

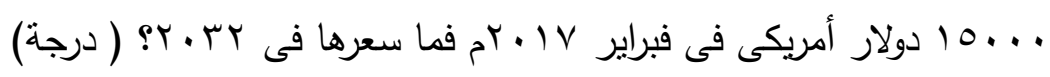

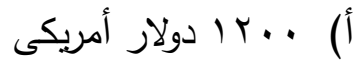

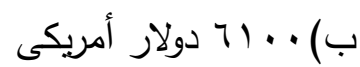

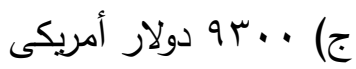

$$
\begin{aligned}
& \text { د) . .0. دـ دولار أمريكى دولار أريكى }
\end{aligned}
$$


أودع رجل مبلغ من المال . . . 10 فى أحد البنوك التى تعطى فائدة سنوية مركبة قدرها أوجد جملة هذا المبلغ بعد مرور · ل سنوات فى كل من الحالات الآتية.

$$
\begin{aligned}
& \text { - العائد السنوى ( درجة ) }
\end{aligned}
$$

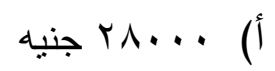

$$
\begin{aligned}
& \text { ب) } \\
& \text { ج) } \\
& \text { د) } \\
& \text { 9- العائد الربع سنوى ( درجة) } \\
& \text { جنيه (أ) VAr09.VV } \\
& \text { ب) } \\
& \text { ج) } 9 \text { ج.rr. . } \\
& \text { د) } \\
& \text { • 1- العائد الثهرى ( درجة ) } \\
& \text { أ) } \\
& \text { ب) } \\
& \text { ج) (جNV700.9 جنيه } \\
& \text { د) . }
\end{aligned}
$$

السؤال الثانى : ضع علامة صع أو خطأ ( عشرة درجات)

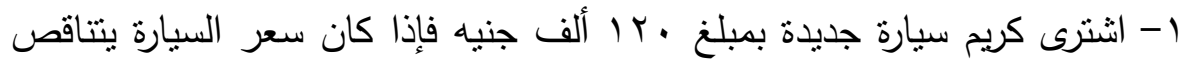

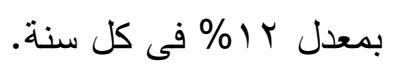

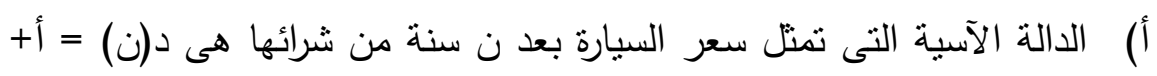

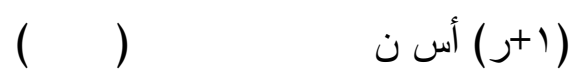

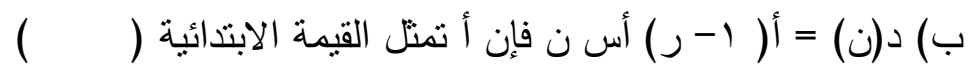

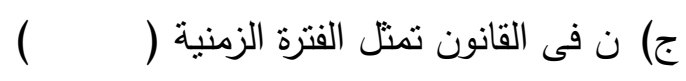

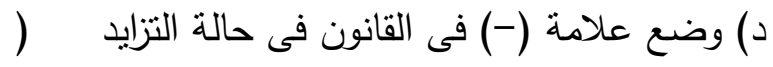

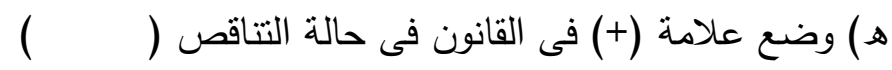


نموذج تصحيح الاختبار التحصيلى

أولاً:- إجابة أسئلة الاختيار من متعدد

\begin{tabular}{|c|c|c|c|c|}
\hline د & ج & ب & أ & الرقم \\
\hline & & $\checkmark$ & & 1 \\
\hline & & & $\checkmark$ & $r$ \\
\hline & & $\checkmark$ & & r \\
\hline & & & $\checkmark$ & $\varepsilon$ \\
\hline & & $\checkmark$ & & 0 \\
\hline$\checkmark$ & & & & 7 \\
\hline$\checkmark$ & & & & V \\
\hline & & $\checkmark$ & & $\wedge$ \\
\hline & $\checkmark$ & & & $q$ \\
\hline & & & $\checkmark$ & 1. \\
\hline
\end{tabular}

ثانياً: إجابة أسئلة الصواب والخطأ

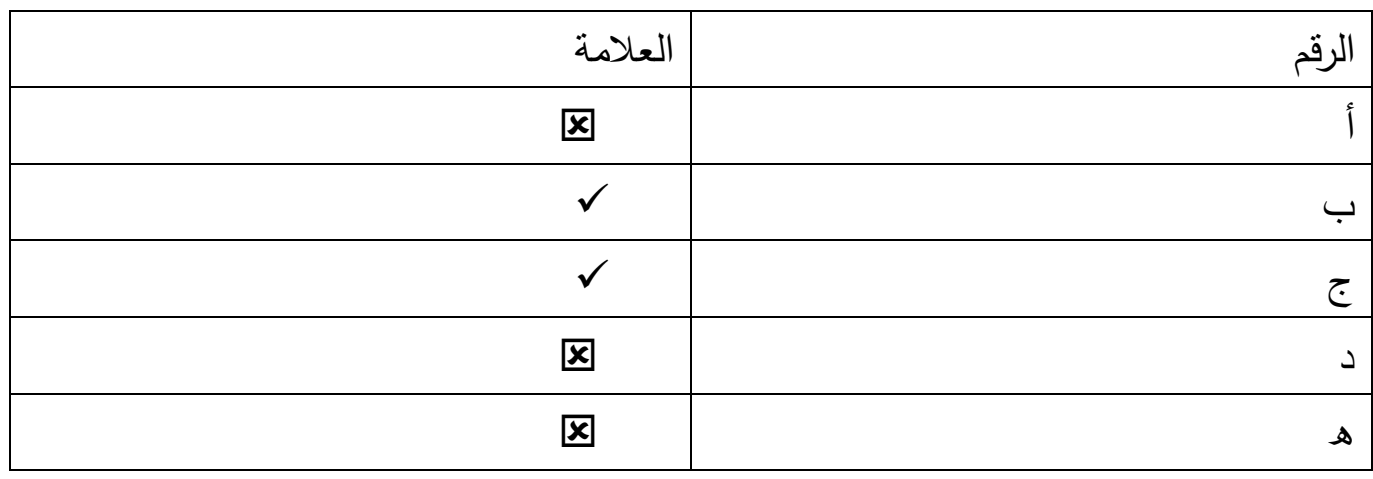




\section{الملحق الثانى ( نص المسرحية )}

( مسرحية : الاستثمار حاجة العصر )

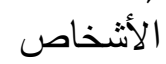

1- محمود ( صاحب معرض سيارات)

r- بالد محمود

ץ- عادل ( مدير حاسبات معرض سيارات)

ع - حسين ( موظف بمعرض سيارات ) مدات

- - بهاء ( مدير شركة استثمار )

4- كريم ( أحد موظفى شركة الاستثمار )

المشهر الأول

( في منزل ، يدخل محمود والأب جالساً على أريكة)

محمود: السلام عليكم يا أبى في معزي

الأب : وعليكم من السلام يامحمود ، تعالى أجلس ، أخبارك إئا إيه وأخبار المعرض.

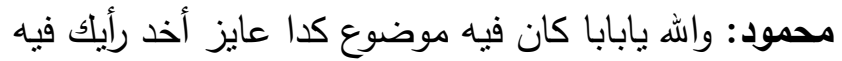
الأب: خير

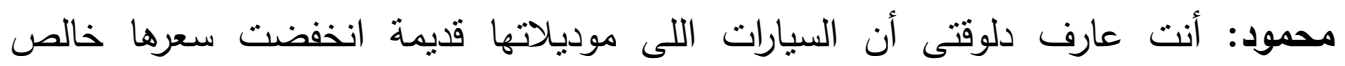

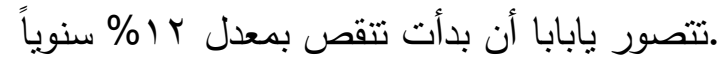

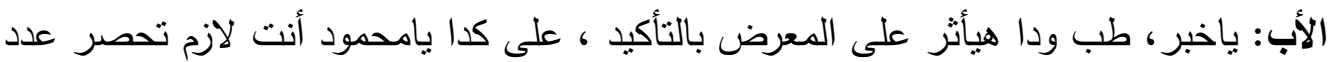

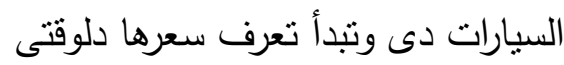
محمود : مش مهم اعرف سعرها دلوقتى ، أنا عايز اعرف دوف سعرها بعد بعد خمس سنوات وخصوصاً

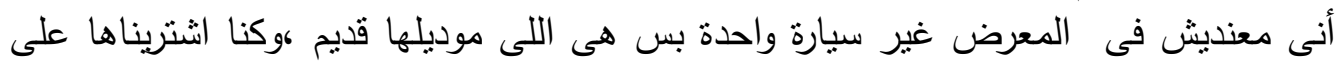

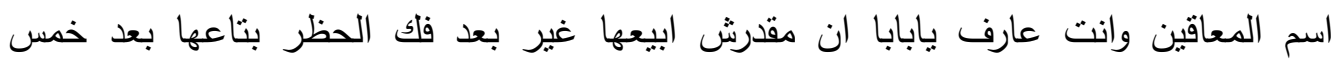

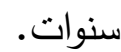

الأب: تمام ، طب أنت لازم بامحمود تعرف سعرها كام من دلوقتى بعد الخمس سنوات دول محمود: ماهو دام اللى أنا بف لأنكر فيه الأب: دا موضوع مهم فعلا ، طب دانا عندى انتراح عشان نقدر نعرف سعرها بعد الخمس سنوات محمود: قول يابابا

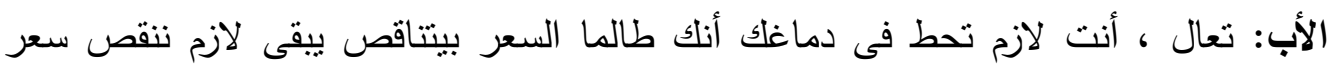

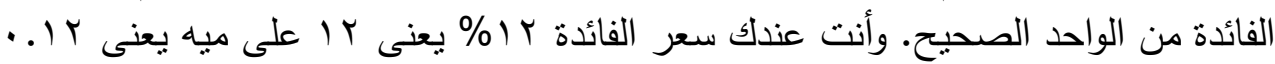

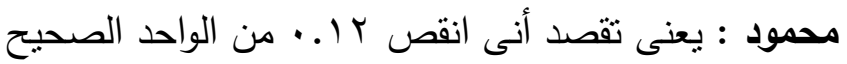

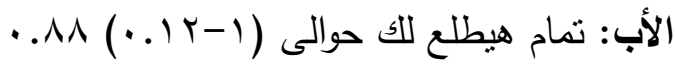


محمود: وطبعاً يابابا دا الأساس اللى هشتغل عليه واحط دايما فترتى الزمنية على شكل أس

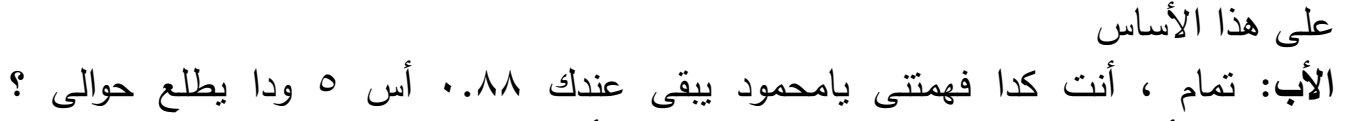

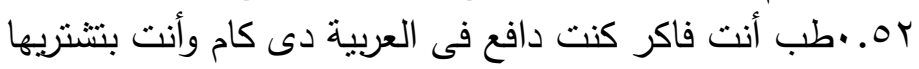

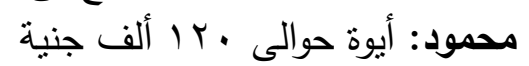

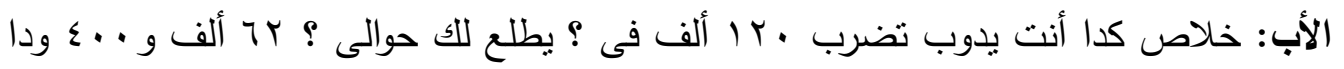

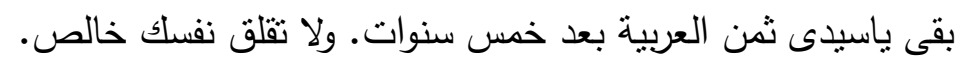

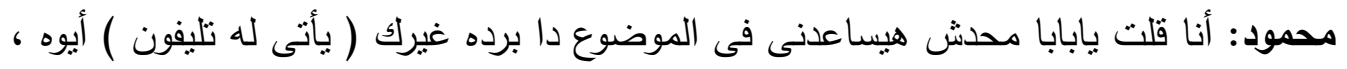

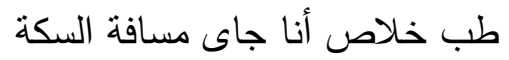
الأب: فيه حاجة بامحمود أنام

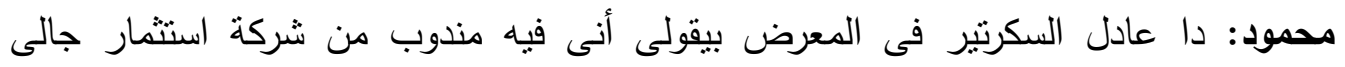

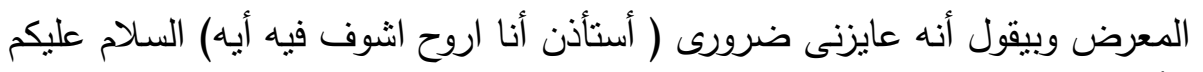
المشهد الثانى الأب: وعليكم من السلام

( فم معرض السيارات المندوب يجلس أمام السكرتير ياخل محمود)

محمود: السلام عليكم كريم : وعليكم من السلام علئم

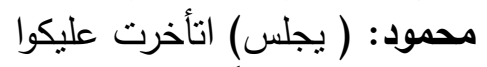

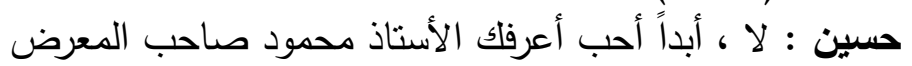

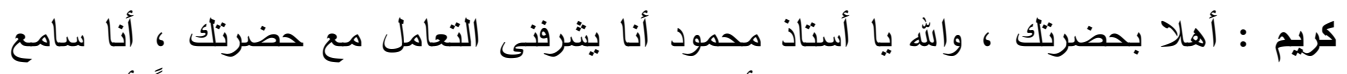

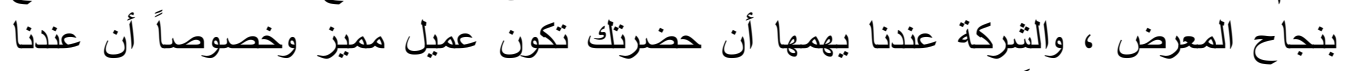

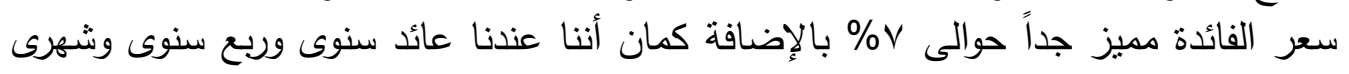
كمان

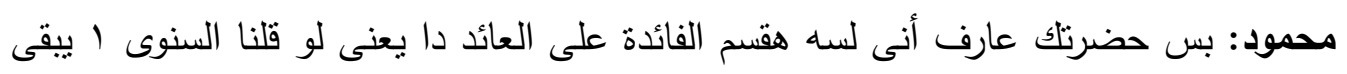

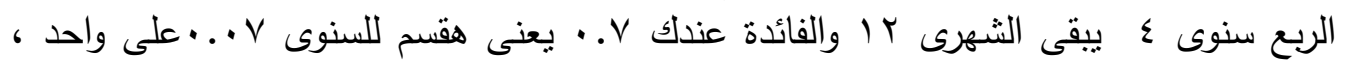

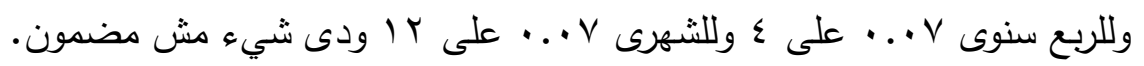

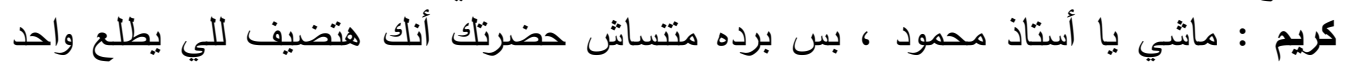

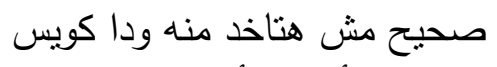

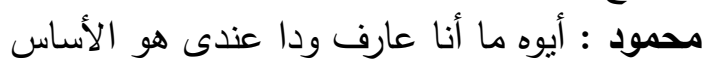

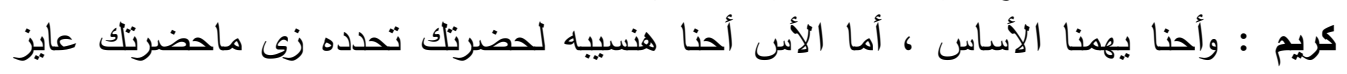

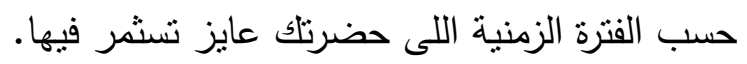


محمود: أنا دايما بحب استثر أى أموال للمعرض على ددة · ل1 سنوات. بس برده انتوا

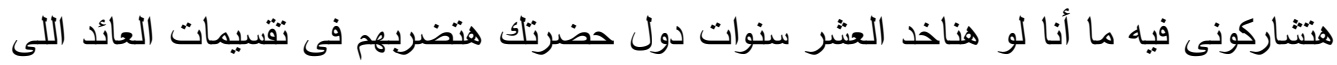

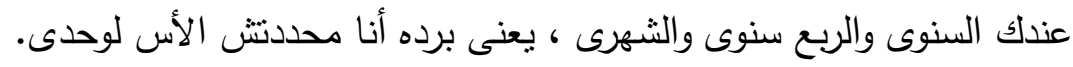

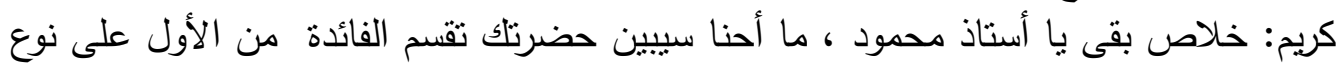

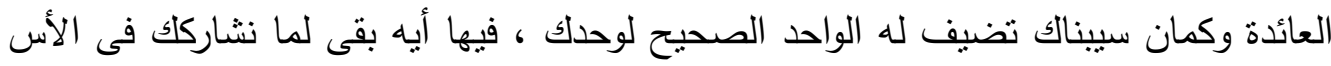

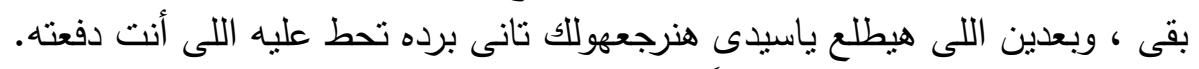

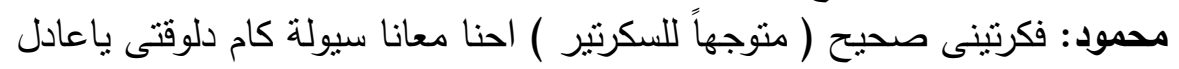

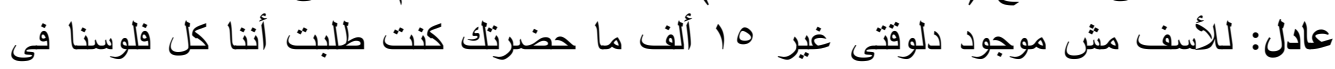
البنوك.

محمود: تمام ، مفيش مشكلة ( موجها للمندوب) هيعملوا كام دول بعد عشر سنوات

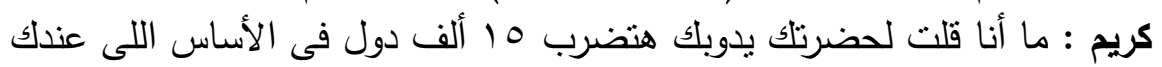

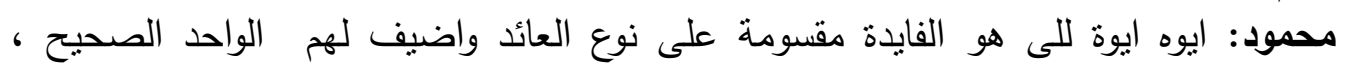

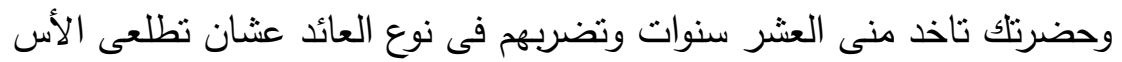

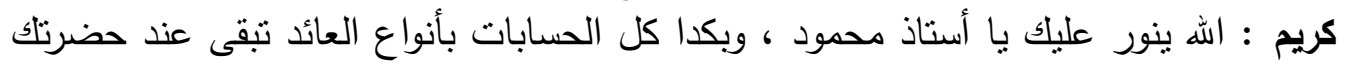

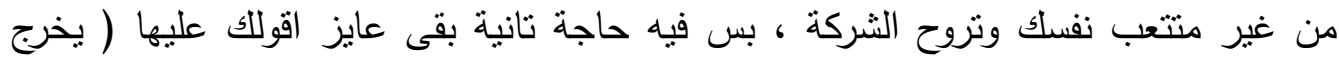

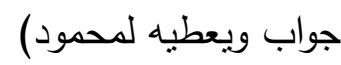
محمود : خير كريم: الشركة عاملة دعوة احتفالية لأول عميل معانا ، عايزين حضرتلك تزور الثركة وتقييم

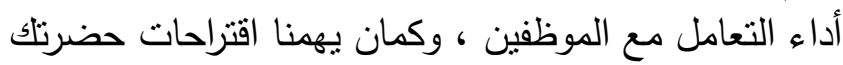

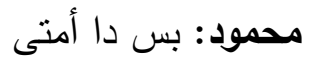
كريم: بكرة بإذن اله ، اسيبكم أنا بقى وشكراً على تعاونكم معانا ( ينهض واقفاً)

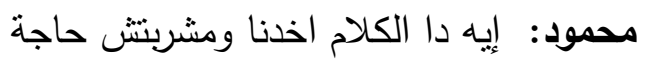

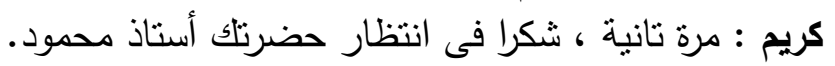
محمود: إن شاء الله كريم : السلام عليكم المشهب الثالث محمود وعليكم من السلام عل مرئ

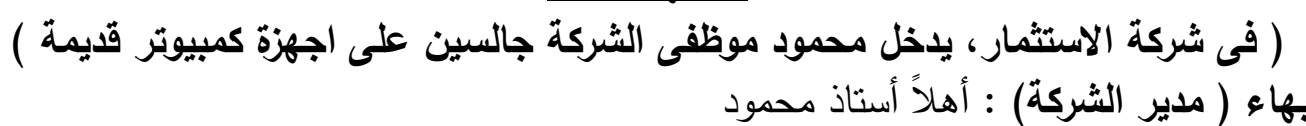

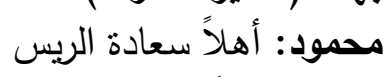

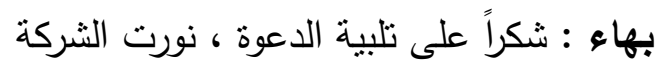

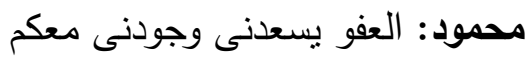

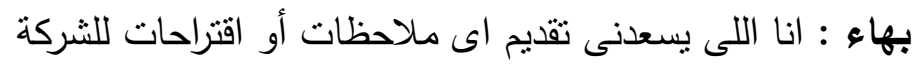


محمود: واله انا مش عندى اقتراحات دلوقتى وخصوصاً انى دى أول زيارة للمكان ، ويمكن لما

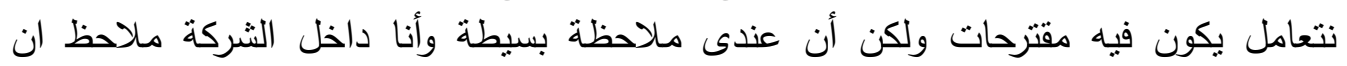

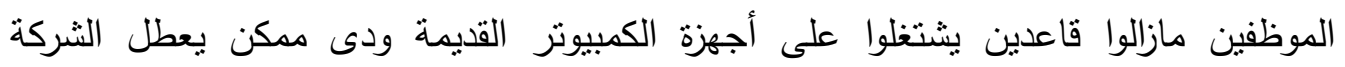

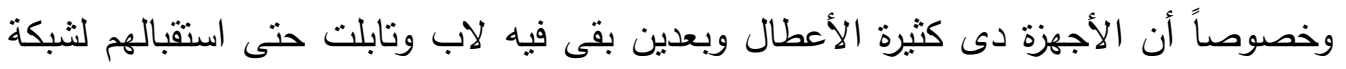

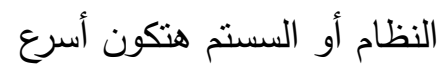
بهاء : عندك حق يا أستاذ محمود ، ملاحظة جميلة بس أنا قلت ألت ابدأ بالأجهزة دى عشان

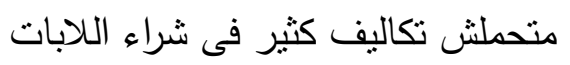
محمود: حضرتك لو حسبتها هتلاقى نفسك الكسبان لأن الأجهزة دى سعرها بيقل والاجهزة

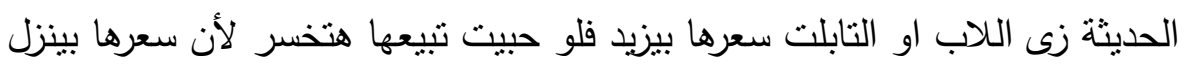

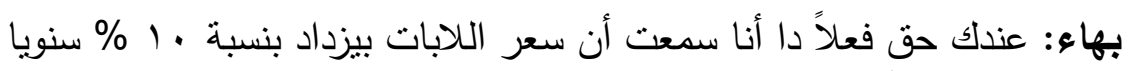

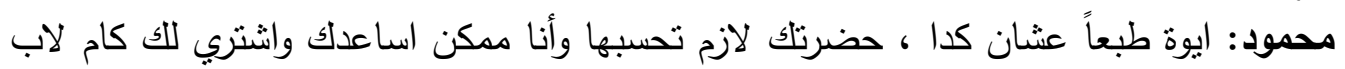

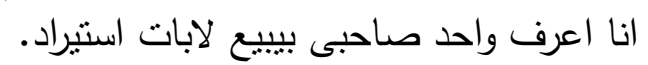

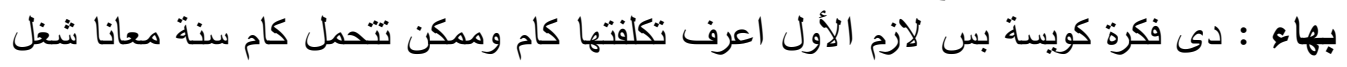

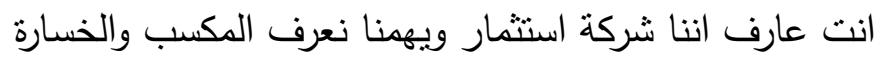

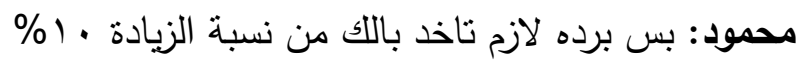

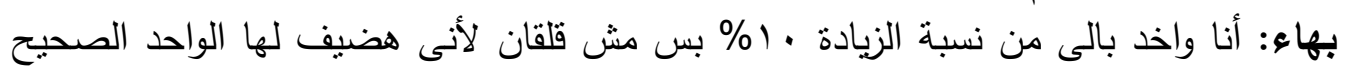
مش هاخد منها. محمود: طب نمام من منام

بهاء: المهم بس حضرت متك تساعدنا أستاذ محمود وتشترى لينا لابات بسعر كويس

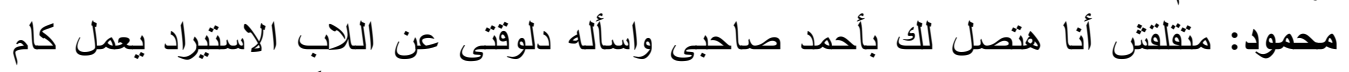

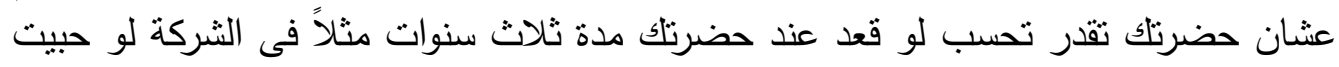
تبيعه بعمل كام بهاء: اتفقنا محمود(يتصل ) أيوه احمد اخبارك ايه ، تمام بخير والله ، كنت عايزة أسألك عندك لألابات

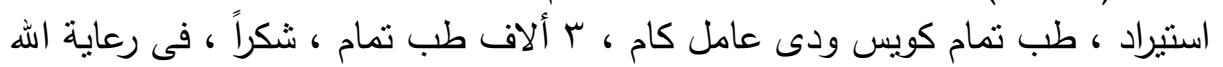

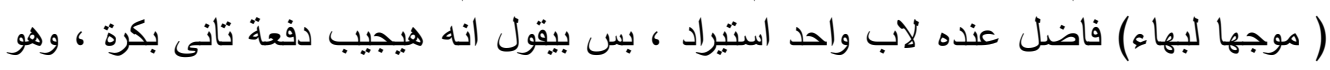

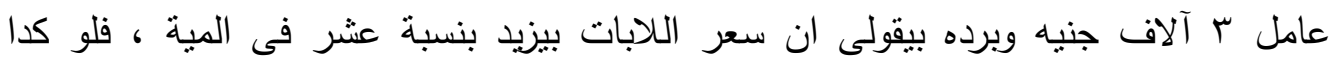

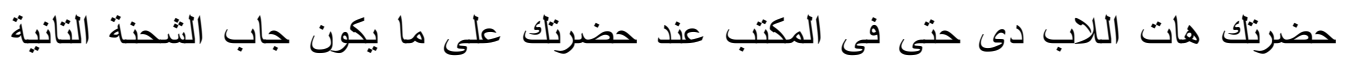
تشترى لموظفين الثركة. بهاء: أنا معاك بس أنا لازم اعرف سعر الاب دى لو جيت ابيعه بعد r سنوات مثلا اللى

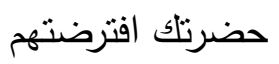

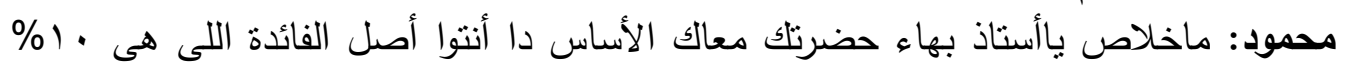

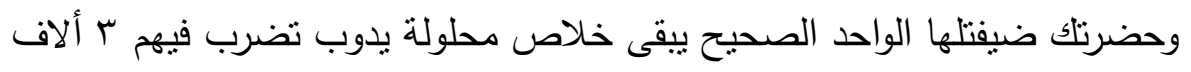


بهاء: بس انت ناسي انك انت اللى محدد الفترة الزمنية ب سنوات

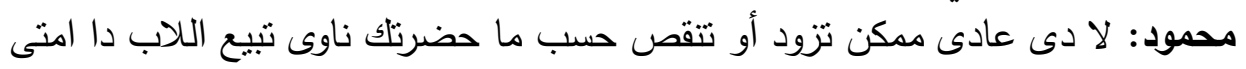

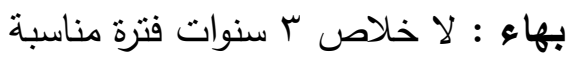

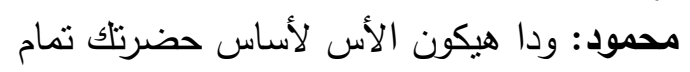

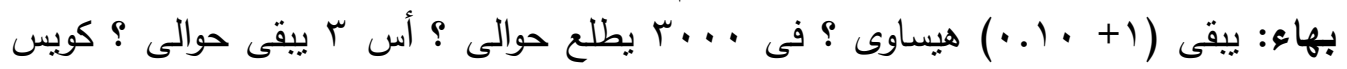
سعر معقول أهم حاجة انه مش هيخسر انت عارف أستاذ محمود انتا يهمنا الربح فالاستثمار عنوانا.

محمود: مش عنوانك بس الاستثمار لازم يقيى عنوان أى حد دا بقى حاجة العصر .

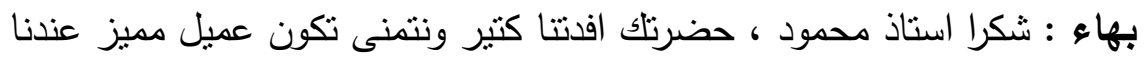

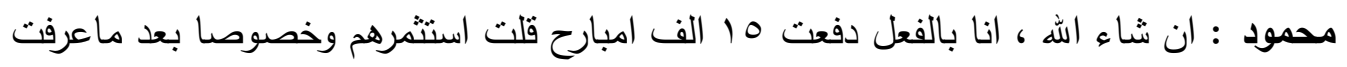

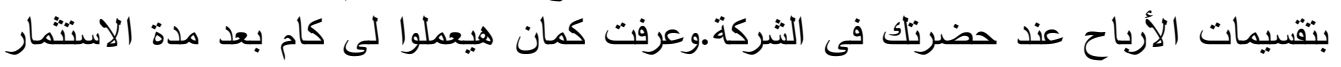
اللى أنا عايزها. بهاء: طب تمام ، ونتمنى تزود قيمة التعامل إن إن شاء الله

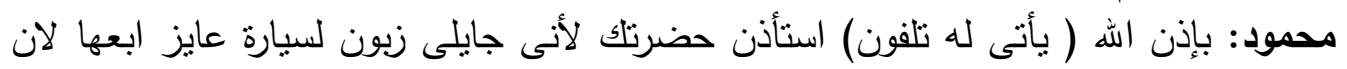

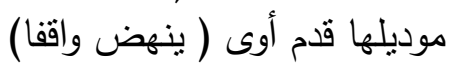
بهاء: شرفتتا استاذ محمود ، وان شاء ألهاء الهه هبعت حد دلوقتى يجيب لنا اللاب طالما سعره بيزيد

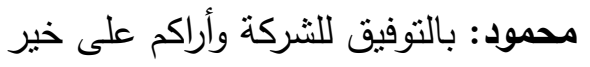
النهاية 


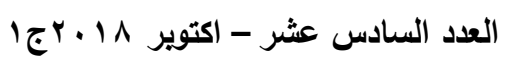

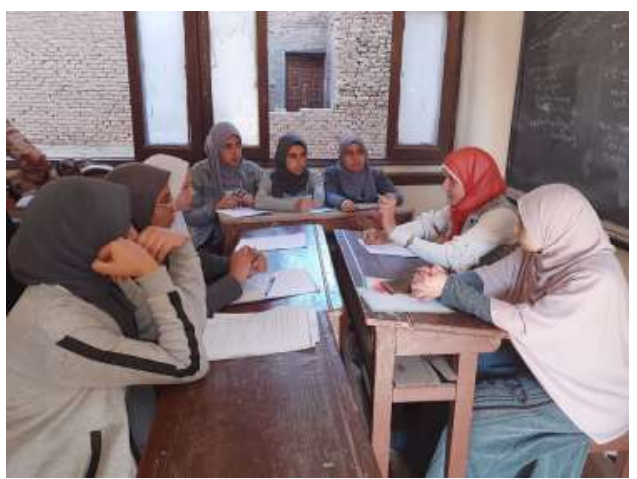

مشهح تدريبات المنضدة التى تتضمن توزيع نسخ النص والقراءة وشملت توضيح طبيعة الدور لكل طالبة.

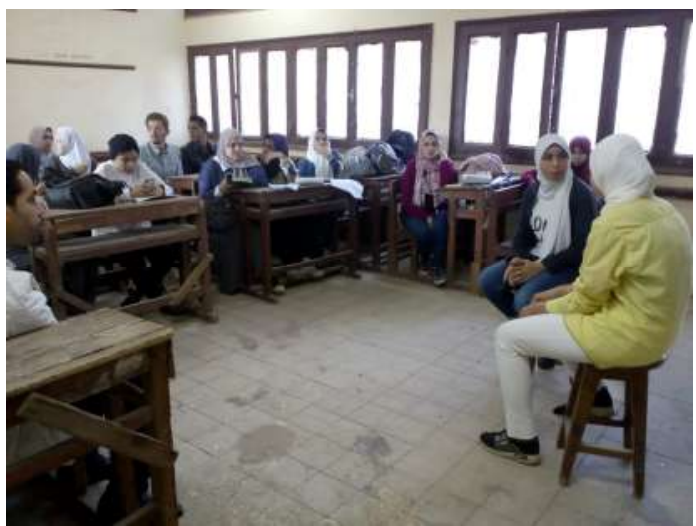

مشهد وقد تم رسم الفصل على شكل حرف U واستخدام مقدمة الفصل كمساحة للتمثيل والممرات لاخول وخروج الطالبات أثناء التمثيل.

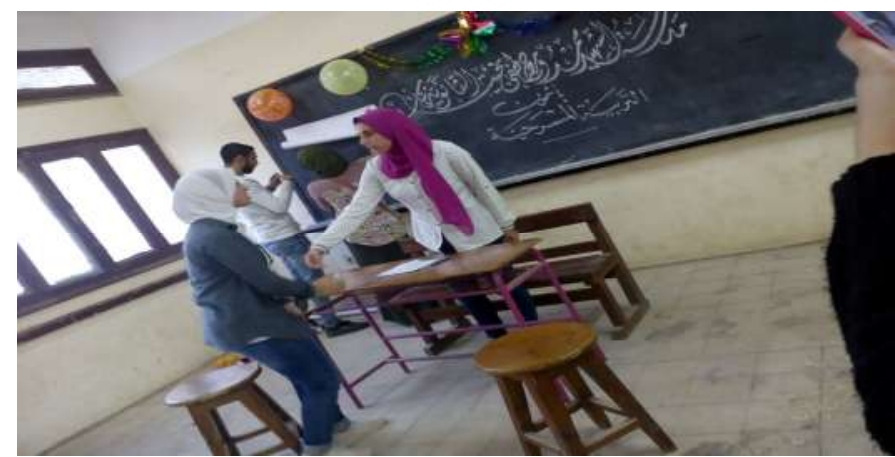

مشهد يوضح أولى تدريبات الحركة للطالبات وكيفية تعليق الديكورات واستخلال السبورة لوضع يافطات توضتح مكان الأحداث. 


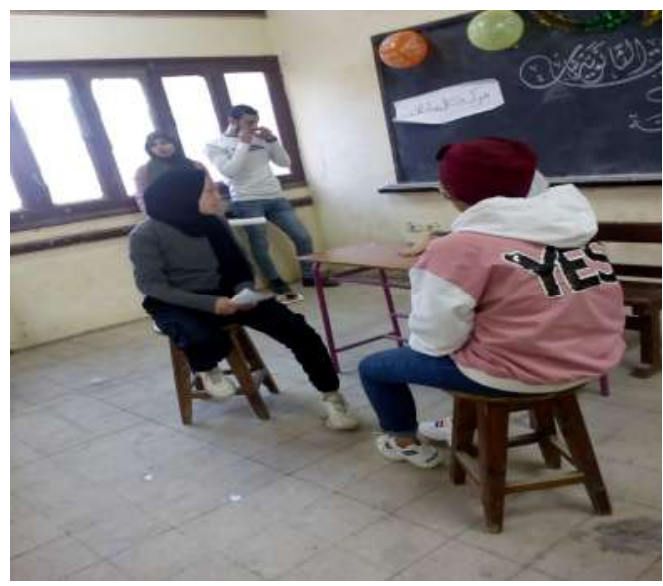

صورة توضع استخدام أثنات الفصل كديكورات للمسرحية ، فقد تم استخدام السبورة لتعليق يافطة باسم شركة الاسثمار ، كما تم استخدام مقاعد الطالبات مكتب.

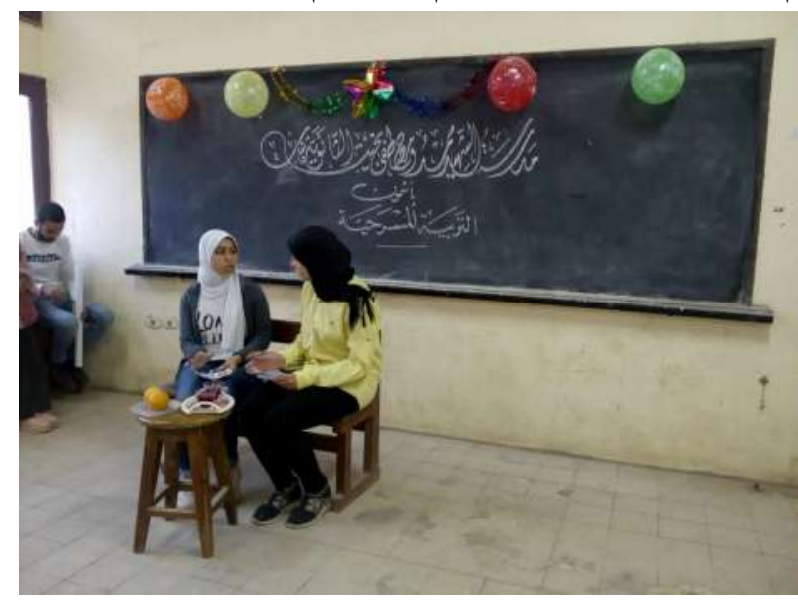

مشهد من العرض النهائي 